\title{
Evaluation of ARM tethered-balloon system instrumentation for supercooled liquid water and distributed temperature sensing in mixed-phase Arctic clouds
}

\author{
Darielle Dexheimer ${ }^{1}$, Martin Airey ${ }^{2}$, Erika Roesler $^{1}$, Casey Longbottom ${ }^{1}$, Keri Nicoll ${ }^{2,5}$, Stefan Kneifel ${ }^{3}$, Fan Mei $^{4}$, \\ R. Giles Harrison ${ }^{2}$, Graeme Marlton ${ }^{2}$, and Paul D. Williams ${ }^{2}$ \\ ${ }^{1}$ Sandia National Laboratories, Albuquerque, New Mexico, USA \\ ${ }^{2}$ University of Reading, Dept. of Meteorology, Reading, UK \\ ${ }^{3}$ University of Cologne, Institute for Geophysics and Meteorology, Cologne, Germany \\ ${ }^{4}$ Pacific Northwest National Laboratory, Richland, Washington, USA \\ ${ }^{5}$ University of Bath, Dept. of Electronic and Electrical Engineering, Bath, UK
}

Correspondence: Darielle Dexheimer (ddexhei@sandia.gov)

Received: 25 March 2019 - Discussion started: 7 May 2019

Revised: 5 August 2019 - Accepted: 20 August 2019 - Published: 20 December 2019

\begin{abstract}
A tethered-balloon system (TBS) has been developed and is being operated by Sandia National Laboratories (SNL) on behalf of the U.S. Department of Energy's (DOE) Atmospheric Radiation Measurement (ARM) User Facility in order to collect in situ atmospheric measurements within mixed-phase Arctic clouds. Periodic tethered-balloon flights have been conducted since 2015 within restricted airspace at ARM's Advanced Mobile Facility 3 (AMF3) in Oliktok Point, Alaska, as part of the AALCO (Aerial Assessment of Liquid in Clouds at Oliktok), ERASMUS (Evaluation of Routine Atmospheric Sounding Measurements using Unmanned Systems), and POPEYE (Profiling at Oliktok Point to Enhance YOPP Experiments) field campaigns. The tethered-balloon system uses helium-filled $34 \mathrm{~m}^{3}$ helikites and 79 and $104 \mathrm{~m}^{3}$ aerostats to suspend instrumentation that is used to measure aerosol particle size distributions, temperature, horizontal wind, pressure, relative humidity, turbulence, and cloud particle properties and to calibrate ground-based remote sensing instruments.
\end{abstract}

Supercooled liquid water content (SLWC) sondes using the vibrating-wire principle, developed by Anasphere Inc., were operated at Oliktok Point at multiple altitudes on the TBS within mixed-phase clouds for over $200 \mathrm{~h}$. Sondecollected SLWC data were compared with liquid water content derived from a microwave radiometer, Ka-band ARM zenith radar, and ceilometer at the AMF3, as well as liquid water content derived from AMF3 radiosonde flights. The in situ data collected by the Anasphere sensors were also compared with data collected simultaneously by an alternative SLWC sensor developed at the University of Reading, UK; both vibrating-wire instruments were typically observed to shed their ice quickly upon exiting the cloud or reaching maximum ice loading. Temperature sensing measurements distributed with fiber optic tethered balloons were also compared with AMF3 radiosonde temperature measurements. Combined, the results indicate that TBSdistributed temperature sensing and supercooled liquid water measurements are in reasonably good agreement with remote sensing and radiosonde-based measurements of both properties. From these measurements and sensor evaluations, tethered-balloon flights are shown to offer an effective method of collecting data to inform and constrain numerical models, calibrate and validate remote sensing instruments, and characterize the flight environment of unmanned aircraft, circumventing the difficulties of in-cloud unmanned aircraft flights such as limited flight time and inflight icing. 


\section{Introduction}

Understanding microphysical properties of persistent Arctic mixed-phase stratiform clouds is a critical factor in accurately representing the radiative energy balance in climate models (e.g., Morrison et al., 2012; Jouan et al., 2012; Shupe et al., 2013). In particular, supercooled liquid water content (SLWC) within these clouds has great significance in determining the radiation balance between the surface and clouds (e.g., Shupe and Intrieri, 2004), as well as presenting a potential in-flight icing hazard to aircraft (e.g., Fernández-González et al., 2014). Supercooled liquid water measurements within clouds have been collected using manned aircraft (e.g., Gultepe and Isaac, 1997), but typically not in the Arctic, where operational concerns and the frequent occurrence of these clouds within $2 \mathrm{~km}$ of the surface present additional challenges. Surface-based microwave radiometers are widely used to monitor the temporal evolution of liquid water path, i.e., the vertically integrated amount of liquid water, inside these mixed-phase clouds (e.g., Crewell et al., 2009). Liquid water has no absorption line in the microwave spectrum, however, so these instruments cannot directly provide information on the distribution of the SLWC vertically inside the cloud, which is key for radiation and ice microphysics. Development of a tethered-balloon system was supported by the U.S. Department of Energy's (DOE) Atmospheric Radiation Measurement (ARM) program in order to collect semi-regular, in situ measurements of aerosol properties, cloud microphysical information, and thermodynamic structure within Arctic clouds while avoiding the expense and potential risk of manned aircraft flights.

Tethered-balloon systems have been used to collect tropospheric atmospheric measurements for over 40 years, including profiles of biogenic compounds, chemical species, turbulence, radiation, cloud microphysics, and meteorological parameters (e.g., Morris et al., 1975; Owens et al., 1982; Greenberg et al., 1999; Knapp et al., 1998; Lawson et al., 2011; Egerer et al., 2019). Morris et al. (1975) developed a portable tethered-balloon system that essentially behaved as a tethered radiosonde that was able to be operated by one person at altitudes up to $750 \mathrm{~m}$ above ground level (a.g.l.) in wind speeds as high as $10 \mathrm{~m} \mathrm{~s}^{-1}$. Owens et al. (1987) advanced the capabilities of tethered-balloon systems by creating a system capable of lifting $2.75 \mathrm{~kg}$ to $800 \mathrm{~m}$ a.g.l. that was used to collect meteorological data and ozone concentrations. Greenberg et al. (1999) further promoted tetheredballoon system development by deploying sampling packages used to measured biological volatile organic compounds in the mixed layer in a series of deployments conducted over 11 years. Knapp et al. (1998) combined tethered-balloon system and kite measurements to study the anticorrelation between ozone and water vapor mixing ratios. Lawson et al. (2011) deployed a tethered-balloon system (TBS) with a cloud particle imager and $4-\pi$ radiometer up to $1.6 \mathrm{~km}$ m.s.l. at Ny-Ålesund and $0.8 \mathrm{~km}$ at South Pole Station. Most re- cently, Egerer et al. (2019) operated sets of instruments to measure turbulent, energy, and radiative fluxes to altitudes of $1.5 \mathrm{~km}$ a.g.l. within Arctic clouds.

Use of tethered-balloon systems can be limited by the very meteorological conditions that would be desirable to operate during however, including elevated wind speeds, wind speed, directional shear, and convective updrafts and downdrafts. Additionally, outside of restricted airspaces tethered-balloon systems are often unable to receive aviation authority approvals in the US to operate near or within clouds, to altitudes higher than $1 \mathrm{~km}$ above ground level, or in reduced surface visibilities. The work discussed herein pertains to the new capability of using tethered-balloon systems within restricted airspace for persistent, repeatable, interannual flights inside Arctic mixed-phase clouds, with supercooled liquid water sondes and distributed temperature sensing optical fiber systems.

Vibrating-wire-based devices for measuring supercooled liquid water on radiosondes have been in development since the 1980s (e.g., Hill and Woffinden, 1980; Hill, 1994). In the past decade vibrating-wire-based supercooled liquid water content radiosonde flights have been conducted concurrently with a collocated microwave radiometer, ceilometer, and Kaband radar to validate the sonde-measured vertical profile of supercooled liquid water (e.g., Serke et al., 2014; King et al., 2016). Advancing this approach, supercooled liquid water content sondes from two manufacturers were operated on the ARM TBS at multiple altitudes within Arctic clouds simultaneously for over $200 \mathrm{~h}$, in order to collect comparatively higher spatially and temporally resolved data than were available from radiosonde balloon flights. Supercooled liquid water measurements from collocated sondes from one manufacturer, which were operated simultaneously on the TBS, were used to estimate the measurement uncertainty. Liquid water path from the zenith-pointing microwave radiometer at Oliktok Point was adiabatically distributed through a single cloud layer using the ceilometer-determined cloud base and Ka-band radar-determined cloud top altitudes for intercomparison.

The microwave radiometer does not discriminate between liquid and supercooled liquid and is insensitive to ice and snow at frequencies lower than $90 \mathrm{GHz}$, so a high-resolution temperature profile is desirable when conducting comparisons of SLWC sonde and radiometer measurements within Arctic clouds composed of cloud water in both conditions; where water that continues to exist in a liquid state at temperatures below $0^{\circ} \mathrm{C}$ is considered supercooled. In addition to radiosonde-based measurements of temperature from each SLWC sonde, near-continuous measurements of temperature were collected using a fiber optic distributed temperature sensing (DTS) system. DTS provides greatly improved spatial and temporal resolution of temperature compared to radiosonde measurements and allows measurements to be collected continuously between the balloon and the surface for the duration of the tethered-balloon flight. Distributed 
temperature sensing has been shown to be an effective method of collecting atmospheric temperature measurements (e.g., Keller et al., 2011; Thomas et al., 2012; de Jong et al., 2015), but has been limited in the duration, altitude, and ambient conditions of measurement. DTS was used to provide submeter vertical profiles of temperature between the surface and the balloon every 30 to $60 \mathrm{~s}$. The present paper discusses tethered-balloon-based distributed temperaturesensing measurements and their comparison with concurrent AMF3 radiosonde temperature measurements under cloudy and clear conditions to altitudes over $1 \mathrm{~km}$ above the surface. An overview of the tethered-balloon system is provided, followed by descriptions of the SLWC sondes and DTS system, subsequent flight results from Oliktok Point, and a discussion of future operational plans.

\section{Tethered-balloon system (TBS)}

\subsection{TBS components}

The TBS may be driven by a continuously rated $5.3 \mathrm{kN}$ DCpowered winch and reversible speed controller or smaller electric winches depending on the mission and the balloon in use. The most commonly used winch deploys over $2 \mathrm{~km}$ of Plasma ${ }^{\circledR} 12$ strand synthetic rope, which has a minimum breaking strength of $2494 \mathrm{~kg}$ (Cortland Company, 2019). Allsops $34 \mathrm{~m}^{3}$ helikites (Fig. 1) are a balloon-kite hybrid that use lighter-than-air principles to obtain initial lift, and then a kite to achieve stability and dynamic lift. In the ARM TBS, helikites are typically used for flights with desired altitudes to $700 \mathrm{~m}$ a.g.l., a maximum payload of less than $10 \mathrm{~kg}$, and surface wind speeds less than $11 \mathrm{~m} \mathrm{~s}^{-1}$. SkyDoc ${ }^{\mathrm{TM}}$ and Drone Aviation Corp 79-104 $\mathrm{m}^{3}$ aerostats use a skirt to maintain orientation and stability in flight. Aerostats are generally used when the desired maximum flight altitude is higher than $600 \mathrm{~m}$, the payload is $10-25 \mathrm{~kg}$, and surface wind speeds are less than $8 \mathrm{~m} \mathrm{~s}^{-1}$ (see Dexheimer, 2018, for a full description of the TBS).

\subsubsection{TBS operations}

The TBS was operated with multiple instrument payloads.

This paper focuses on the TBS flight listed in Table 1, which used SLWC sondes and DTS at the AMF3 at Oliktok Point, Alaska, for almost $337 \mathrm{~h}$ from October 2015 to September 2018. Flights occurred during daylight to altitudes of $1.45 \mathrm{~km}$ a.g.l. and with durations from 1 to $9 \mathrm{~h}$ in various atmospheric conditions including clear sky, broken to overcast clouds, rain, sleet, snow, and temperatures from -20 to $25^{\circ} \mathrm{C}$.

\subsection{TBS Anasphere SLWC sondes}

SLWC sondes developed by Anasphere Inc. were operated on the TBS with both InterMet (iMet) radiosondes and Ana-

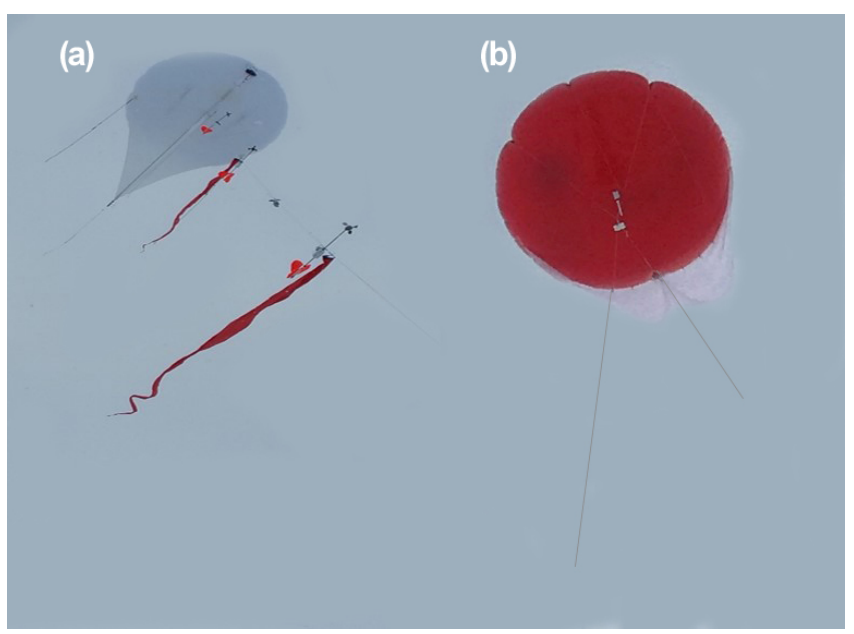

Figure 1. A $34 \mathrm{~m}^{3}$ helikite in flight with three tethersondes (left) and $79 \mathrm{~m}^{3}$ aerostat in flight with radar calibration sphere (right).

sphere tethersondes (Fig. 2). The vibrating wires on the SLWC sondes were oriented orthogonally to the free-stream direction, meaning they were oriented perpendicularly to the surface on the TBS. The rate of change of the frequency of the $0.61 \mathrm{~mm}$ diameter steel vibrating wire on the SLWC sonde and other atmospheric parameters were used to calculate supercooled liquid water based on Eq. (1), where $b_{0}$ is the vibrating-wire mass per unit length of $2.24 \mathrm{~g} \mathrm{~m}^{-1}, f_{0}$ is the un-iced wire frequency in hertz, $f$ is the wire frequency in hertz at time $t, \epsilon$ is the droplet collection efficiency between 0 and 1 found using the method described in Lozowski et al. (1983), $D$ is the wire diameter in meter, and $\omega$ is the velocity of the air relative to the wire in meters per second.

SLWC $=-\frac{2 b_{0} f_{0}^{2}}{\epsilon D \omega f^{3}} \frac{\mathrm{d} f}{\mathrm{~d} t}$

The raw wire frequencies had outliers removed if the frequency deviated over $0.1 \mathrm{~Hz}$ from a $30 \mathrm{~s}$ moving average of the frequency, and the remaining frequencies were then smoothed using the robust LOESS (locally estimated scatterplot smoothing) model. Wind speeds from the Doppler lidar (e.g., Riihimaki et al., 2014) at the AMF3 or tetherbased anemometers were used in the calculation. Pressure, temperature, and relative humidity values from iMet radiosondes (e.g., Dexheimer et al., 2017) were typically used in the collection efficiency calculation, if radiosonde measurements were unavailable tethersonde-measured values of these parameters were used. An estimate of median droplet diameter, $d_{0}$, was required for the collection efficiency calculation. SLWC was calculated using median droplet diameters of 11, 16, and $20 \mu \mathrm{m}$ based on Lozowski et al. (1983) and Bain and Gayet (1982), with results for a median droplet diameter of $16 \mu \mathrm{m}$ being presented here. At wind speeds $\geq 5 \mathrm{~m} \mathrm{~s}^{-1}$, which were typical during TBS flights, a median droplet diameter of $16 \mu \mathrm{m}$ results in a collection ef- 
Table 1. Overview of TBS flights analyzed within this study including date, duration, sensor payload, and campaign.

\begin{tabular}{lrll}
\hline Dates & $\begin{array}{r}\text { TBS } \\
\text { flight } \\
\text { hours }\end{array}$ & Relevant sensors & Campaign \\
& 33.5 & SLWC sondes & ERASMUS \\
\hline 22-28 October 2015 & 9.3 & SLWC sondes & AALCO, ERASMUS \\
3-20 April 2016 & 14.8 & SLWC sondes, Sensornet Oryx DTS & AALCO, ERASMUS \\
13-16 May 2016 & 24.0 & SLWC sondes, Sensornet Oryx DTS & AALCO, ERASMUS \\
5-11 June 2016 & 7.4 & Sensornet Oryx DTS & AALCO, ERASMUS \\
24-27 July 2016 & 33.0 & SLWC sondes, Sensornet Oryx DTS & AALCO, ERASMUS \\
10-20 October 2016 & 10.5 & SLWC sondes & AALCO \\
14-17 November 2016 & 8.5 & SLWC sondes & AALCO, ERASMUS \\
2-10 April 2017 & 30.8 & SLWC sondes, Sensornet Oryx DTS with fiber optic rotary joint (FORJ) & AALCO, ERASMUS \\
15-24 May 2017 & 17.0 & SLWC sondes, Sensornet Oryx DTS with fiber optic rotary joint (FORJ) & AALCO, ERASMUS \\
4-9 August 2017 & 9.7 & SLWC sondes, Silixa XT DTS with fiber optic rotary joint (FORJ) & AALCO, ERASMUS \\
13-22 October 2017 & 41.8 & SLWC sondes, Silixa XT DTS with fiber optic rotary joint (FORJ) & POPEYE \\
1-11 July 2018 & 43.5 & SLWC sondes, Silixa XT DTS with fiber optic rotary joint (FORJ) & POPEYE \\
24 July-3 August 2018 & 22.9 & SLWC sondes, Silixa XT DTS with fiber optic rotary joint (FORJ) & POPEYE \\
17-26 August 2018 & 29.5 & SLWC sondes, Silixa XT DTS with fiber optic rotary joint (FORJ) & POPEYE \\
21-28 September 2018 & 336.2 & & \\
\hline Total & & & \\
\hline
\end{tabular}

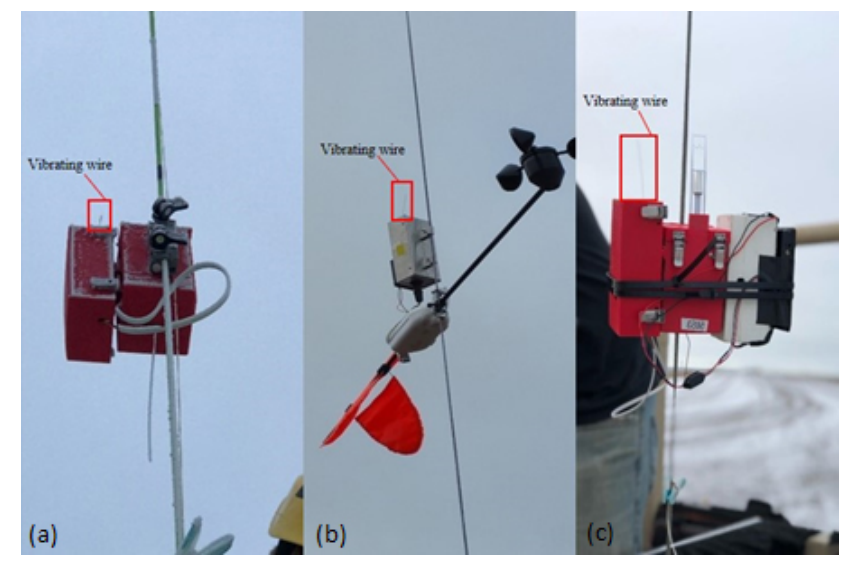

Figure 2. Anasphere SLWC sonde left of InterMet radiosonde on TBS tether (a). Anasphere SLWC sonde above Anasphere tethersonde (b). InterMet radiosonde in center with Anasphere SLWC sonde on left and Reading SLWC sonde on right (c).

ficiency greater than $\sim 0.9$. Therefore, we use this diameter to get the lower estimate of SLWC in all deployments so as provide the most conservative estimates given our lack of particle size knowledge. The three median droplet diameters had limited impact on the resulting calculated SLWC, with mean SLWC values for each TBS flight being within $\pm 0.01 \mathrm{~g} \mathrm{~m}^{-3}$ when all other values were kept constant and the median droplet diameter was varied. A full discussion of the Anasphere SLWC sonde measurement theory and design is available in Serke et al. (2014) and King et al. (2016).

Another SLWC detector, developed at the University of Reading, UK (Airey et al., 2017), was operated alongside the Anasphere sensor on some of the deployments to provide independent comparison and validation. This sensor was designed with programmable versatility in mind. It was also designed with disposability for routine radiosonde use, by implementing complex onboard processing on relatively cheap hardware. The device operates on the same principle as the Anasphere sensor, that is, a vibrating wire that determines mass accretion (ice) from a reduction in natural oscillation frequency; however it is highly versatile, with programmable onboard processing that measures the frequency in three different ways. Implemented methods to determine the resonant frequency include a fast Hartley transform (FHT), a frequency sweep, and a phase-locked loop (see Airey et al., 2017, for a full description of these methods). This experiment combined the FHT and frequency sweep modes, the former providing fast identification of the broad region of frequency $( \pm 0.2 \mathrm{~Hz})$ and the latter using this to focus the sweep region for more rapid resonance detection, which also provides a much higher precision $( \pm 0.005 \mathrm{~Hz})$. Outlier removal and data smoothing are also required for this sensor, in this case a fitting method, that uses a 1st-order polynomial and achieves a better fit to the data given the longer update time when compared with the Anasphere sensor, which uses the 2nd-order polynomial fit; both implementations use the fitting models defined in Mathworks' MATLAB version 2018b. The SLWC is calculated using the same method as that for the Anasphere device. In contrast to the Anasphere design, which mechanically actuates the wire, the Reading design uses a piezoelectric device to both drive the wire and measure the frequency after the drive ceases, thereby eliminating all moving parts. The sensors were flown with the collecting wire horizontal, to better sense the lateral airflow. This 
sensor is designed to relay the data through a radiosonde via the PANDORA interface, also developed at Reading (Harrison et al., 2012). In normal operation the data are transmitted via the standard radiosonde telemetry; for this study, it was adapted to function as a stand-alone unit, self-logging to an SD card.

\subsubsection{Anasphere SLWC sonde uncertainty}

Throughout the ICARUS and AALCO campaigns pairs of eight different Anasphere SLWC sondes were operated side by side, in the presence of SLW clouds, for over $4 \mathrm{~h}$. Three such comparison flights were conducted with SLWC sondes on the TBS, while one flight was conducted using a freeflight meteorological balloon. The SLWC values calculated at simultaneous times for each SLWC sonde pair are presented in Fig. 3 to depict the noise or relative uncertainty in the Anasphere sonde measurements, and the corresponding probability density functions of the SLWC values from each sensor are shown in Fig. 4. The mean differences between simultaneous nonzero SLWC values calculated by all sonde pairs operated on the TBS were 0.01 to $0.02 \mathrm{~g} \mathrm{~m}^{-3}$, and larger for the free-flight balloon pair at $0.06 \mathrm{~g} \mathrm{~m}^{-3}$.

\subsection{Distributed temperature sensing system components}

Two DTS systems were used on the TBS over the three field campaigns studied. The Sensornet Oryx DTS fires a center wavelength $971 \mathrm{~nm}$ laser pulse lasting less than $10 \mathrm{~ns}$ through attached $50 \mu \mathrm{m}$ multimode optical fibers. Up to four fibers may be deployed from each DTS system simultaneously. Some of the laser light is Rayleigh scattered as it collides with the structure of the fiber and returns down the fiber at the incident wavelength. The portions of the backscattered signal that are shifted towards lower and higher frequencies are considered Stokes and anti-Stokes scattering, respectively. The ratio of anti-Stokes to Stokes photons produced increases with temperature, and their different respective attenuations are combined in order to represent the proportional total return intensity. The velocity of light in the fiber is constant, so the number of nanoseconds between the laser pulse firing and the detection of the returned light can be used to determine the scattering site, and thus the calculated temperature. When DTS is operated on the TBS the scattering site represents an altitude. Under Eq. (2) below, the intensity of the backscattered light $(I)$ is proportional to the difference in the molecular energy state of the photons before and after scattering $(\Delta E)$ divided by the Boltzmann constant $(k)$ and the temperature of the scattering site.

$$
\frac{I_{\text {Stokes }}(z)}{I_{\text {antiStokes }}(z)} \alpha \exp (\Delta E / k T(z))
$$

When the balloon is stationary DTS data may be collected by directly connecting an optical fiber to the DTS system.
However, there are some disadvantages of this configuration for the TBS: at least $20 \mathrm{~min}$ is required to install and remove coils of fiber in calibration baths, there is a potential risk of damage to the fiber whenever it is coiled or uncoiled, and the TBS is required to float at a fixed altitude when vertical profiling may be a more desirable method of operation. To overcome these constraints DTS data may be collected when the balloon is in motion by using a fiber optic rotary joint (FORJ) between the optical fiber and DTS. However, the low loss $(<0.5 \mathrm{~dB})$ required for DTS measurements approaches the limits of most currently available commercial FORJs. Multiple FORJs were tested before successfully collecting accurate DTS measurements through an FORJ by using a spool of fiber deployed with a variable-speed electric motor. The fiber was spooled and unspooled using foot pedals to match the rate of the TBS winch during ascent and descent (Fig. 5). If a significant temperature differential does not exist between the surface and lowest few meters of the atmosphere, a method of demarcating the surface is helpful in determining the starting location of the suspended portion of fiber with respect to the portion of fiber remaining on the spool. Various methods of surface demarcation were tested and a saltwater bath proved to be the most ideal solution.

A Sensornet Oryx DTS system was used prior to October 2017, with a $30 \mathrm{~s}$ measurement interval and $1 \mathrm{~m}$ sampling resolution. Single-ended DTS measurements were collected after initially collecting double-ended measurements, due to the reduction in data file size and processing effort related to correlating the deployed fiber length with the balloon altitude, as it is affected by horizontal drag. Approximately $15 \mathrm{~m}$ of fiber were coiled into ice water and hot water calibration baths, with $15 \mathrm{~m}$ of fiber between each bath. A PT100 temperature sensor was placed in each bath and logged by the DTS. An iMet-1-RSB radiosonde measuring temperature every $1 \mathrm{~s}$ was placed at the balloon-end of the fiber to serve as an independent temperature measurement aloft for calibration. In September 2017 a second DTS system, a Silixa XT, was procured. The Silixa XT has a center wavelength of $1064 \mathrm{~nm}$ and is capable of $25 \mathrm{~cm}$ spatial resolution, largely due to a reduction in pulse duration to $2.5 \mathrm{~ns}$, which allowed a smaller section of fiber to be used in the surface calibration baths and demarcation portion.

\section{Results}

\subsection{SLWC results}

\subsubsection{October 2017 SLWC from TBS flight with concurrent SLWC from free-radiosonde launch}

Between 13 October 2017 22:20 UTC and 14 October 2017 00:20 UTC two Anasphere SLWC sondes (e.g., Dexheimer et al., 2016) were operated in the presence of two stratocumulus cloud layers, the lowest with a base at $0.45-0.55 \mathrm{~km}$ 

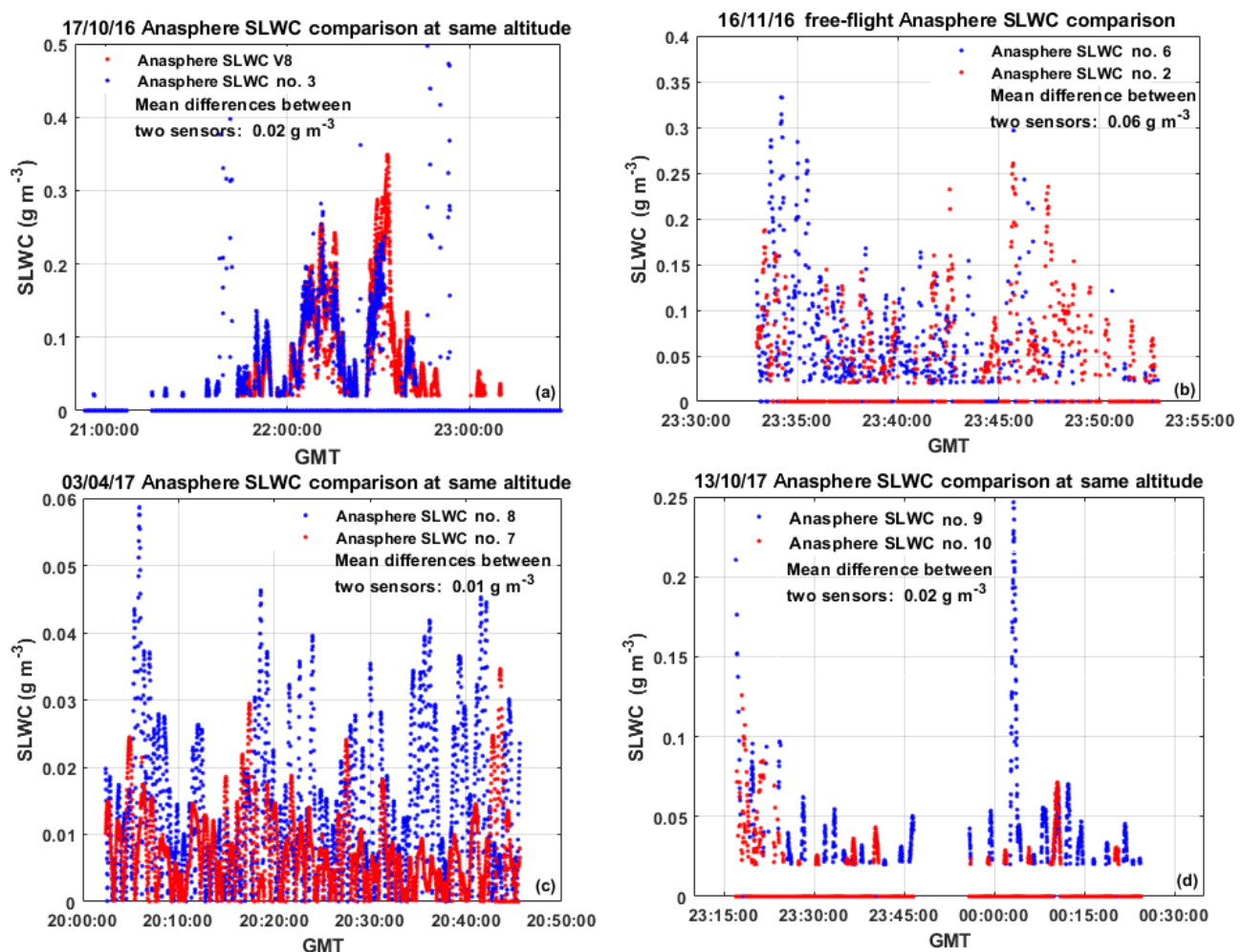

Figure 3. Results of four side-by-side comparison flights of Anasphere SLWC sondes.
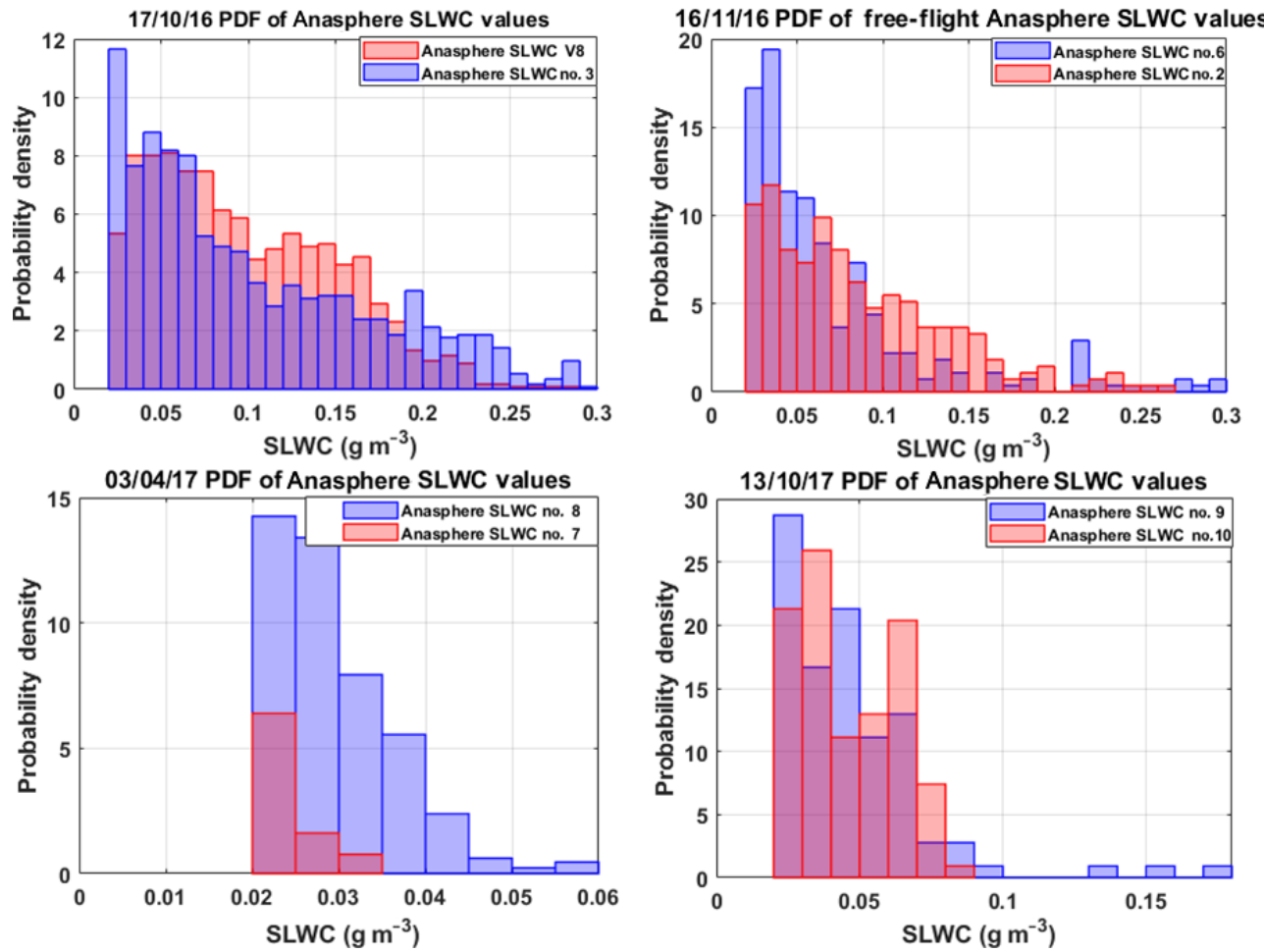

Figure 4. Probability density functions (PDFs) of four side-by-side comparison flights of Anasphere SLWC sondes. 


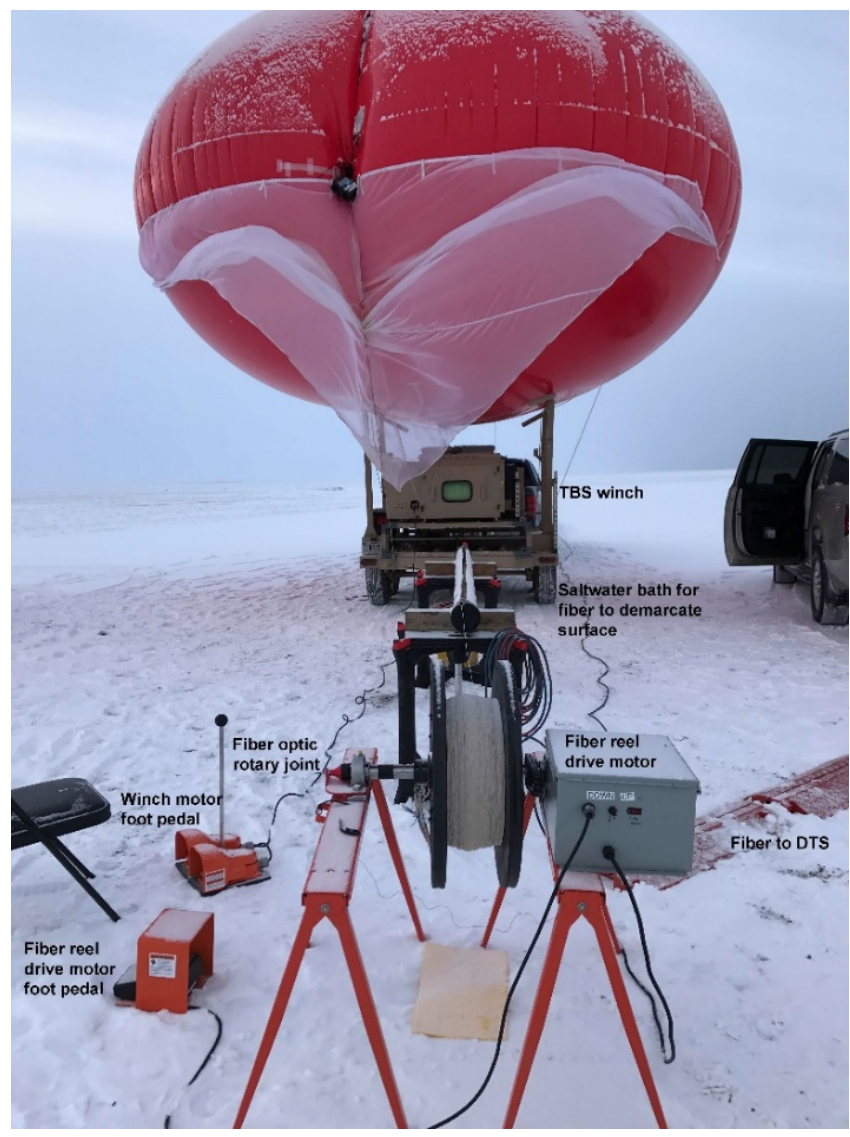

Figure 5. TBS with optical fiber operating through rotary joint and saltwater bath.

and a second with a base at approximately $0.75 \mathrm{~km}$ and a top near $1 \mathrm{~km}$. These cloud layers were representative of the persistent, low-level stratocumulus clouds which commonly occur in the Arctic. A stratocumulus cloud base between 100 $\mathrm{m}$ and $1.2 \mathrm{~km}$ persisted at Oliktok Point for $96 \mathrm{~h}$ between 12 and 16 October 2017. Temperature decreased during the TBS flight from $-2{ }^{\circ} \mathrm{C}$ at the surface to $-5.5^{\circ} \mathrm{C}$ near $600 \mathrm{~m}$.

The ARM AMF3 23:27 UTC sounding, which occurred during the TBS flight, was analyzed using the commercial software RAOB (Fig. 6). Liquid water content (LWC) was calculated from the sounding using the enthalpy equation for cloud water (LWC) in RAOB. This equation uses the adiabatic enthalpy $(\gamma)$ lapse-rate equation, where LWC is a function of air density $\rho(z)$, specific heat at constant pressure $(\mathrm{Cp})$, latent heat of vaporization $(L)$, dry adiabatic lapse rate $\left(\Gamma_{\mathrm{d}}\right)$, and the moist adiabatic lapse rate $\left(\Gamma_{\mathrm{S}}\right)$.

$\operatorname{LWCad}(z)=\int \rho(z) \frac{\mathrm{Cp}}{L}\left(\Gamma_{\mathrm{d}}-\Gamma_{\mathrm{s}}\right) \mathrm{d} z$

The LWC calculated by RAOB, which in this case was considered SLWC since the entirety of the cloud was below $0^{\circ} \mathrm{C}$, increased adiabatically through the cloud, reaching a maximum of $0.32 \mathrm{~g} \mathrm{~m}^{-3}$ just below cloud top at $0.95 \mathrm{~km}$. Su-
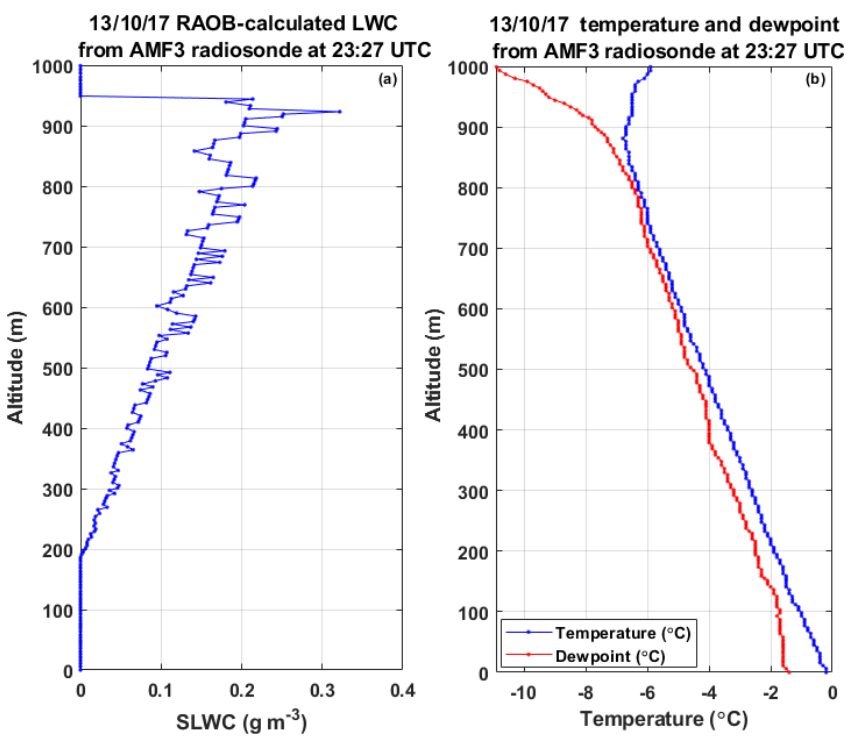

Figure 6. LWC calculated in RAOB software using Eq. (3) for 13 October 2017 23:30 UTC AMF3 sounding (a) and temperature and dew point from sounding (b).

percooled liquid water content was also calculated from the two SLWC sondes operating on the TBS. The LWC values calculated by RAOB from the free-radiosonde flight (e.g., Coulter et al., 2013) at the same altitudes as both tetheredballoon vibrating-wire SLWC sondes were both $0.14 \mathrm{~g} \mathrm{~m}^{-3}$. As shown in Fig. 7 the lowest cloud base reported by the AMF3 ceilometer (e.g., Johnson et al., 2013) between 23:26 and 23:32 UTC had a standard deviation of $120 \mathrm{~m}$ and varied widely from a minimum of $210 \mathrm{~m}$ to a maximum of $740 \mathrm{~m}$. This variation in the cloud base would be expected to cause significant variation in whether or not SLWC was measured by the TBS SLWC sondes. The maximum SLWC observed by the highest-altitude TBS SLWC sonde between 23:26 and 23:32 UTC was $0.14 \mathrm{~g} \mathrm{~m}^{-3}$, while the maximum SLWC observed by the lower-altitude sonde was $0.05 \mathrm{~g} \mathrm{~m}^{-3}$. Given the variation in the cloud base during the flight and the spatial variation between the TBS and AMF3 radiosonde measurements, the TBS SLWC sondes and RAOB LWC calculation showed reasonable agreement.

\subsubsection{The 15 and 20 October 2016 TBS Anasphere SLWC sondes and SLWC from MWR}

For two TBS flights that did not occur during one of the twice-daily AMF3 radiosonde launches, SLWC values measured by TBS Anasphere SLWC sondes were compared with SLWC derived from the surface-based AMF3 microwave radiometer (MWR). These TBS flights occurred in singlelayer, subfreezing stratocumulus clouds on 15 and 20 October 2016. SLWC was derived by distributing MWR (e.g., Cadeddu et al., 2013) liquid water path values adiabatically through the single cloud layer. The cloud layer thickness was 

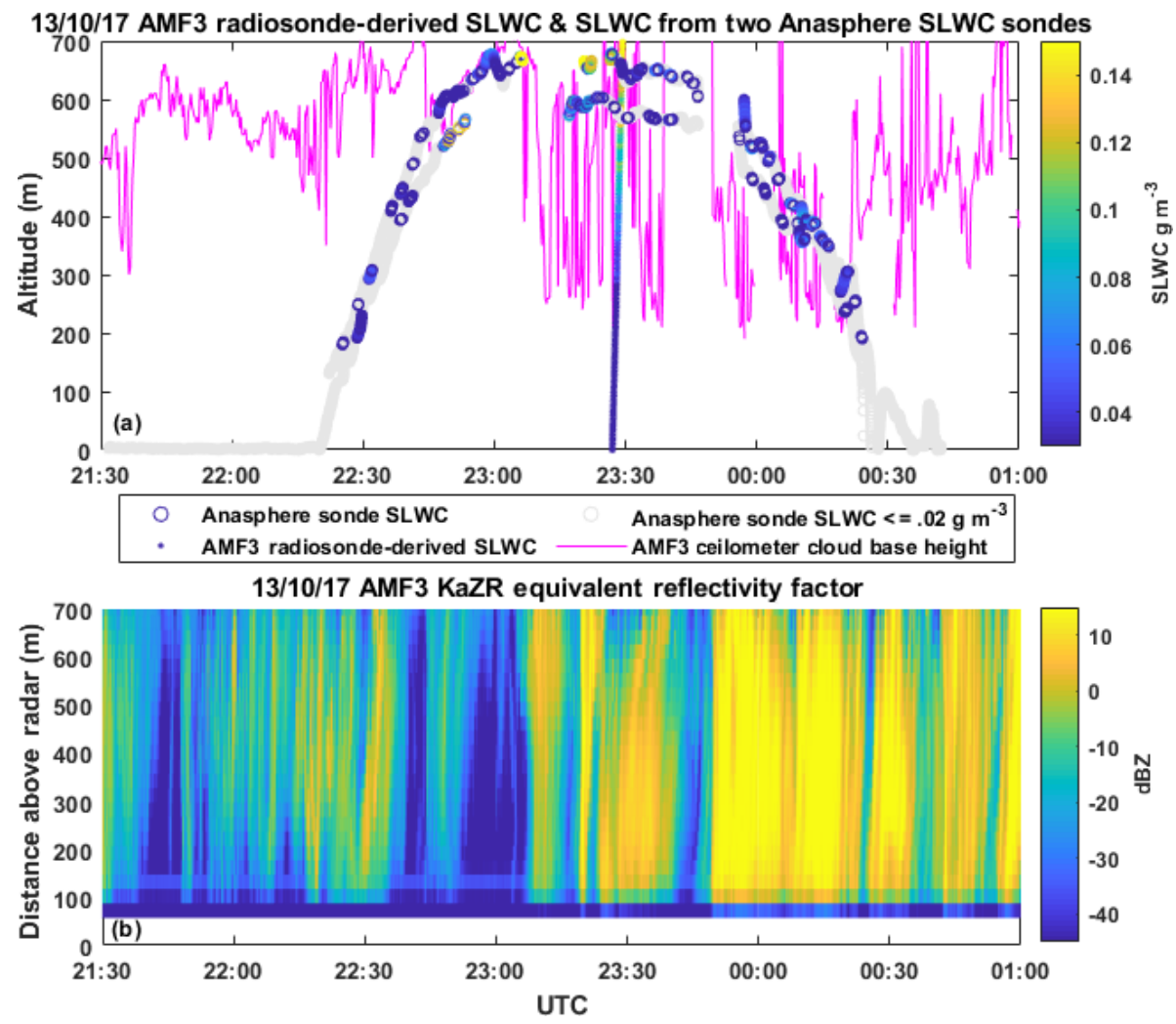

Figure 7. TBS flight of two SLWC sondes with concurrent free-balloon radiosonde launch on 13 October 2017 at 23:27 UTC. In (a) the RAOB LWC values calculated from the 23:37 UTC AMF3 free-radiosonde launch are plotted (dots), as well as SLWC measured by two TBS SLWC sondes (circles), the lowest cloud base height reported by the AMF3 ceilometer (magenta), and the reflectivity from the AMF3 KaZR (b).

defined using the lowest cloud base from the ARM AMF3 ceilometer and cloud top from the ARM ARSC (Active Remote Sensing of Clouds) value-added product (VAP) (e.g., Johnson et al., 2015). The ARSC VAP combines ceilometer data and the deviation of the KAZR reflectivity from received sky noise to assign bases and tops to up to 10 cloud layers. Nonzero SLWC values $\leq 0.02 \mathrm{~g} \mathrm{~m}^{-3}$ were considered to be below the noise threshold of the Anasphere SLWC sonde and removed; then all remaining SLWC values were smoothed with a moving average.

On 15 October 2016 the cloud base altitude deviated significantly with time, resulting in the Anasphere SLWC sondes flying above and below the ceilometer-defined cloud base (Fig. 8). The SLWC values from both sensors were nonzero when in cloud as expected although the magnitude differed, resulting in an $R^{2}$ value of 0.38 . Given the ceilometer cloud height resolution of $\pm 10 \mathrm{~m}$ (e.g., Morris, 2016) and TBS iMet radiosonde GPS altitude resolution of $\pm 15 \mathrm{~m}$, the agreement of SLWC detection between the two sensors is surprisingly good considering the uncertainty regarding the placement of the SLWC sonde with respect to cloud base.

On 20 October 2016 the Anasphere SLWC sonde flew for $2 \mathrm{~h}$ at $150 \mathrm{~m}$ above cloud base, descending to $85 \mathrm{~m}$ above cloud base with time, due to the accumulation of ice on the balloon, sensors, and tether. The Anasphere SLWC sonde experienced multiple shedding events during the flight, where the maximum ice load on the vibrating wire is reached and subsequently shed, resulting in erroneously low SLWC values. The $R^{2}$ value for SLWC values from the flight was 0.79 , with MWR SLWC values averaging $0.03 \mathrm{~g} \mathrm{~m}^{-3}$ higher, largely due to offset low sonde SLWC values during shedding events.

\subsubsection{Comparison of simultaneous in situ SLWC measurements from the Anasphere and Reading sensors on the TBS}

To independently test the validity of the in situ measurements collected by the Anasphere sondes, some balloon flights were instrumented with an additional Reading SLWC sensor so that simultaneous profiles could be taken and compared between the two sensing methods and against the MWR data. One such flight was conducted on 2 August 2018, where the sensors were deployed on the helikite platform through the cloud base to an altitude of $\sim 400 \mathrm{~m}$ and returned to $\sim 150 \mathrm{~m}$ below the cloud base over two cycles, each of around $60 \mathrm{~min}$ duration. Both sensors successfully detected SLW, particu- 

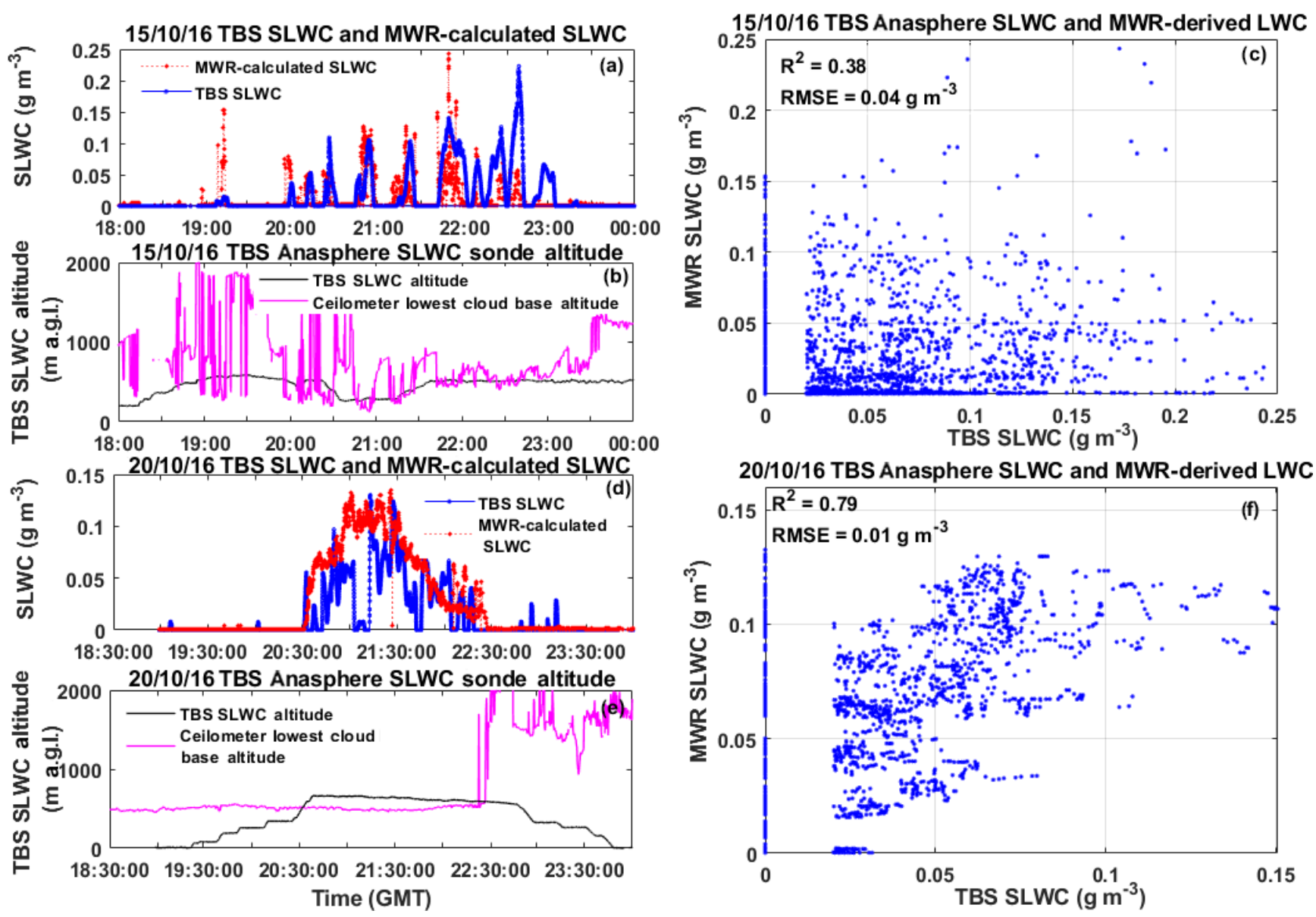

Figure 8. The 15 October 2016 SLWC from TBS Anasphere sonde and calculated from MWR (a), 15 October 2016 TBS Anasphere sonde and ceilometer cloud base altitude (b), and 15 October 2016 SLWC from Anasphere sonde vs. SLWC calculated from MWR (c), 20 October 2016 SLWC from TBS Anasphere sonde and calculated from MWR (d), 20 October 2016 TBS Anasphere sonde and ceilometer cloud base altitude (e), and 20 October 2016 SLWC from Anasphere sonde vs. SLWC calculated from MWR (f).

larly during the ascent and descent phases at approximately 21:00, 21:30, 22:00, and 22:30 UTC. During the initial ascent a gradual increase in SLWC is observed between 200 and $400 \mathrm{~m}$ from 0 to $0.3 \mathrm{~g} \mathrm{~m}^{-3}$. At the maximum altitude, SLWC decreased to $0 \mathrm{~g} \mathrm{~m}^{-3}$ as the sensors emerge into a region of low relative humidity $(\sim 65 \%)$ interpreted to be above the cloud top. During the subsequent descent, both sensors once again detected similar values of SLWC, albeit lower, probably due to either the vibrating wires being at maximum ice loading or descent through an anomalously low-SLW region. The MWR liquid water path (LWP) detected during this descent (Fig. 10) would suggest the former. The closest relationship between the mean and variance of the SLWC values occurs for the Anasphere sonde during the first descent with values of 0.02 and $0.0007 \mathrm{~g} \mathrm{~m}^{-3}$ for the mean and variance, respectively. The second cycle follows the same pattern, with similar SLWC during ascent and above the cloud, although the Reading sensor detected somewhat less SLW during this ascent possibly due to the retention of more ice on the wire than the Anasphere sensor. The final descent also shows reasonably good agreement, peaking at $\sim 0.3 \mathrm{~g} \mathrm{~m}^{-3}$ between 300 and $350 \mathrm{~m}$ as observed in the preceding ascents. Following the final descent, both sensors continue to detect SLW while they are held at $\sim 150 \mathrm{~m}$, somewhat higher than the period following the first descent and, in this case, coinciding periodically with the cloud base, which would account for the continued detection. The higher LWP value detected by the Reading sensor during descent 2 may be due to the longer sensing wire $(120 \mathrm{~mm}$ rather than $90 \mathrm{~mm}$ ) allowing a greater overall detection possible after the shorter wire reaches maximum ice loading, which in King et al. (2016) is suggested as $0.75 \mathrm{~g} \mathrm{~m}^{-3}$ as the response of the wire becomes nonlinear in that environment.

The calculated LWP from each sonde is compared with that derived from the MWR in Fig. 10 and shows both sensors achieving good agreement with the MWR data during the ascents (to within $\pm 0.008 \mathrm{~mm}$ for the Reading sensor and $\pm 0.003 \mathrm{~mm}$ for the Anasphere sensor); however, this is less 


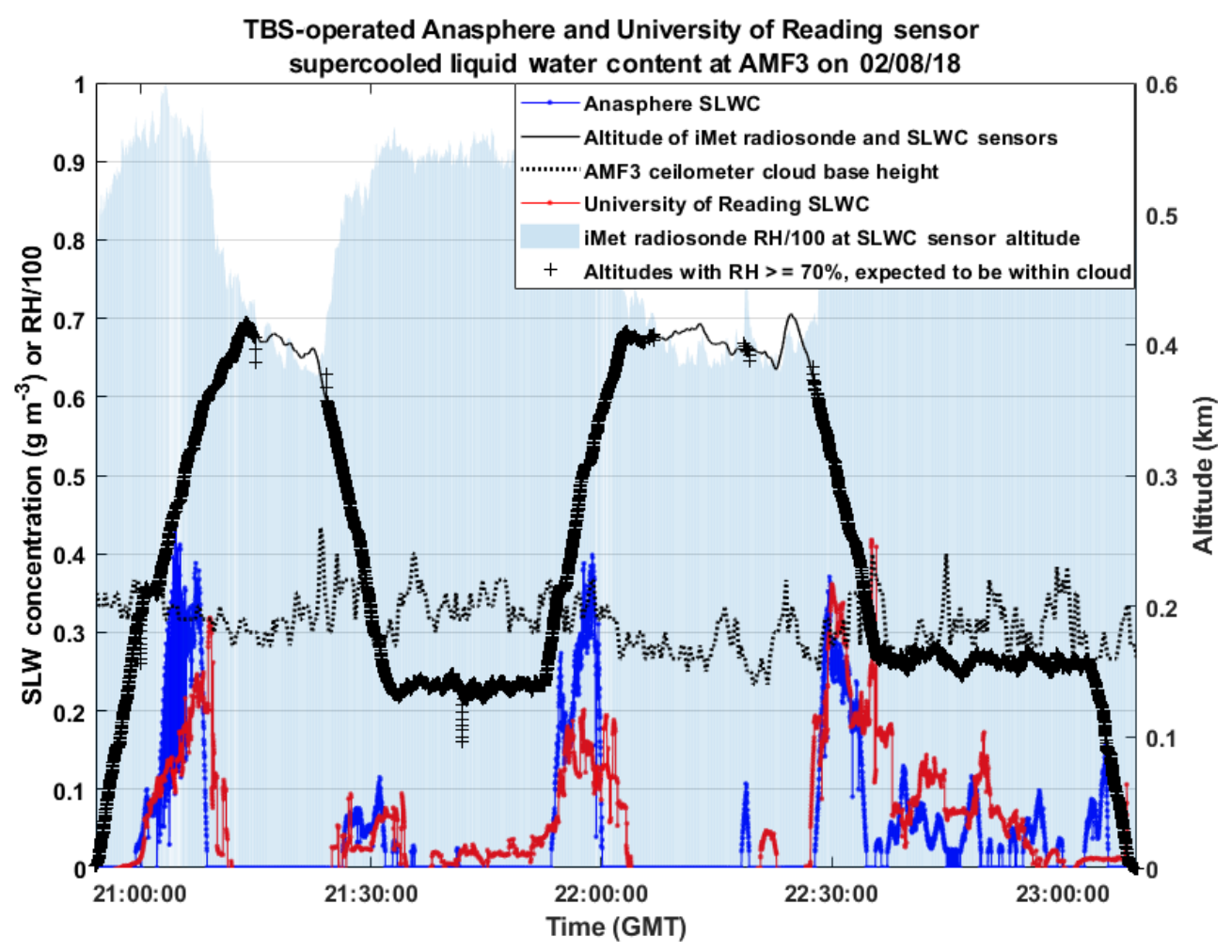

Figure 9. Time series of 2 August 2018 TBS flight with Anasphere and Reading SLWC data, sensor altitude and relative humidity, and cloud base height.

good during the descents for the possible reasons discussed above. Figure 9 shows the time series of the flight and Fig. 10 compares the two SLWC profiles.

Overall, the two sensors seem to provide broadly similar SLWC profiles, but not without some discrepancies. This increases confidence in the use of each of them and provides independent verification of the measurements. The variation between them is partly due to both methods being reliant on different sensor data acquisition methods and physical geometry, but also the sampling conditions of the two sensors may differ. The ice accumulation on the vibrating wire of each sonde may be dependent upon the upwind or downwind orientation of the sonde with respect to the balloon tether. The conversion of the frequency of the wire oscillation to SLWC is also nontrivial depending on the appropriateness of theoretical assumptions, and small differences in frequency data may result in somewhat larger discrepancies in the derived SLWC. The processing of outliers and smoothing of data to allow $\mathrm{d} f / \mathrm{d} t$ to be obtained is another source of sensor-tosensor variation, but, given these considerations, the good agreement between them provides some confidence in their measurements. The Reading sensor has higher precision and sampling frequency than the Anasphere sensor, but is more prone to data gaps. Therefore, the result of the processing algorithms applied will result in sensor-specific nuances.

\subsubsection{Comparison of in situ SLWC Anasphere sonde measurements and SLWC calculated from radiosonde flights}

Mean values of SLWC from the in situ vibrating-wire sondes deployed on the TBS for 43 flights were compared with mean SLWC values calculated from AMF3 radiosonde launches that occurred during each TBS flight at the altitudes of the TBS SLWC sondes using the enthalpy lapse-rate equation for cloud water (LWC) in RAOB shown in Eq. (3).

As shown in Fig. 11 the mean SLWC values measured by the in situ vibrating-wire sondes averaged $0.045 \mathrm{~g} \mathrm{~m}^{-3}$ higher than the mean SLWC values calculated from the radiosonde flights using Eq. (3). Some of this difference could be attributed to temporal and spatial variation between the TBS and radiosonde flights. Despite this, however, the mean SLWC values calculated from Eq. (3) are quite small, at $<0.05 \mathrm{~g} \mathrm{~m}^{-3}$ for $91 \%$ of the dataset. Previous aircraft measurements in supercooled stratiform clouds measured SLWC values $<0.05 \mathrm{~g} \mathrm{~m}^{-3}$ for $36 \%$ of the samples (e.g., University of Wyoming, 1999), which is consistent with the results from the TBS Anasphere sonde measurements. The probability density and cumulative distribution functions of all SLWC data collected with the Anasphere sondes on the TBS for the 43 flights are shown in Fig. 12, and the probability density of SLWC values $<0.05 \mathrm{~g} \mathrm{~m}^{-3}$ was $34 \%$. 


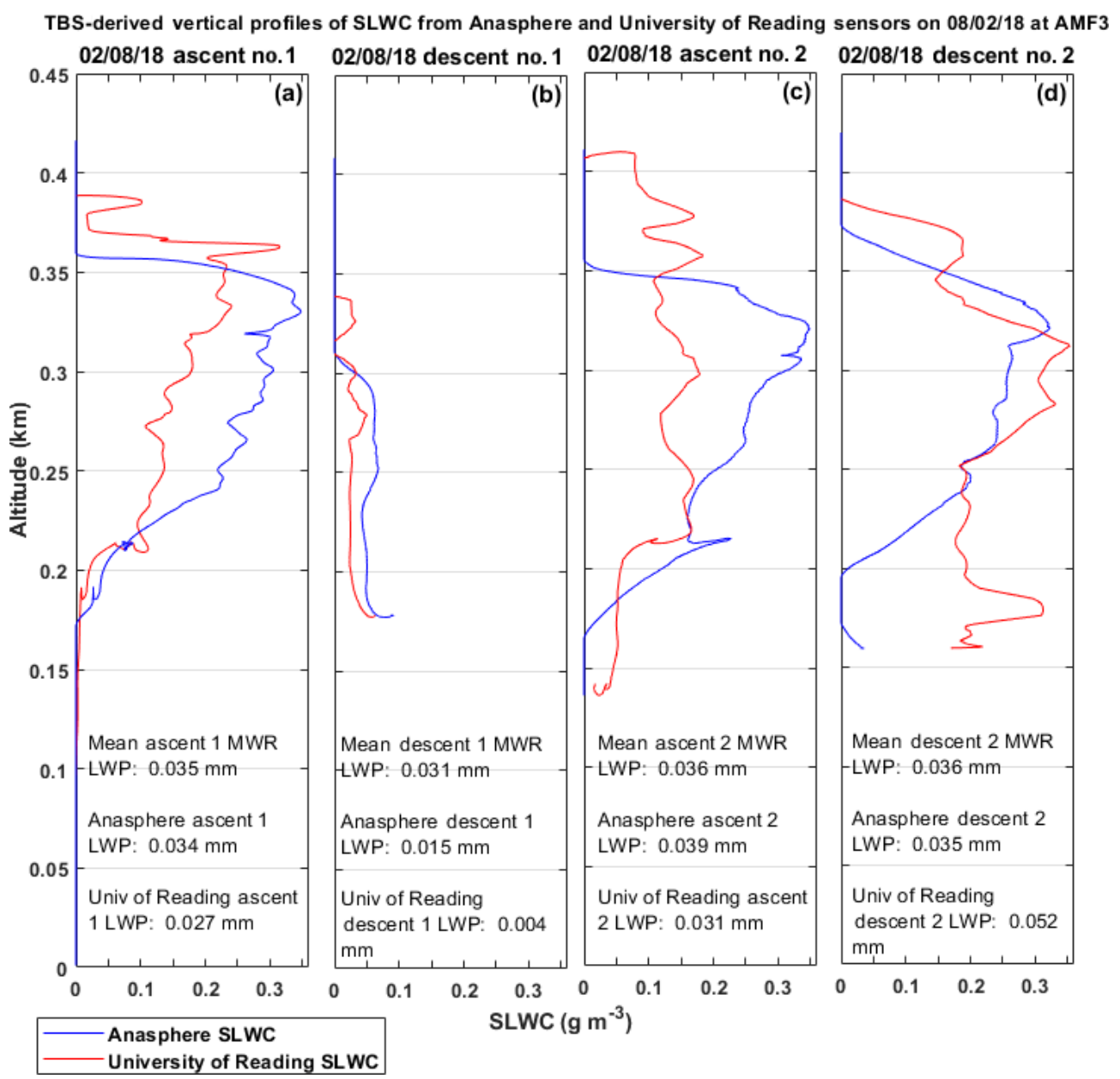

Figure 10. Vertical profiles of Anasphere and Reading SLWC from 02 August 2018 TBS flight with mean surface-based MWR LWP values.

\subsubsection{SLWC from TBS Anasphere sondes from 2015 to 2017 by month, altitude, and temperature}

Figure 13 depicts results from recurring TBS Anasphere SLWC sonde deployments that occurred at the ARM AMF3 during fall and spring months between 2015 and 2017. The highest SLWC values were measured in the late spring during May and June, with lower values being measured in fall and early spring. As shown in Fig. 14 measured SLWC values increased at flight altitudes between $400 \mathrm{~m}$ and $1 \mathrm{~km}$ a.g.l. and were lower below $400 \mathrm{~m}$, and the highest measured SLWC values occurred at temperatures above -14 and below $-2{ }^{\circ} \mathrm{C}$. With respect to interannual variability of SLWC, the mean SLWC values in three sequential Octobers were $0.06,0.10$, and $0.14 \mathrm{~g} \mathrm{~m}^{-3}$; sequential average April values were both $0.05 \mathrm{~g} \mathrm{~m}^{-3}$, and sequential May means were 0.26 and $0.14 \mathrm{~g} \mathrm{~m}^{-3}$, respectively.

\subsection{DTS results}

\subsubsection{The 11 June 2016 DTS measurements with concurrent free-radiosonde launch}

DTS measurements were collected once a minute with a Sensornet Oryx using fiber suspended along the TBS tether from 11 June 2016 21:18 UTC to 12 June 2016 01:19 UTC. During this time a free-flight radiosonde was launched from the AMF3 at 23:30 UTC. The vertical resolution of the radiosonde was approximately $10 \mathrm{~m}$, while DTS measurement vertical resolution was every $1 \mathrm{~m}$. The radiosonde temperature measurement from the altitude closest to each DTS measurement altitude was used for comparison (Fig. 15). The 23:30 UTC radiosonde and DTS temperature measurements between the surface and the maximum altitude of the fiber ( $839 \mathrm{~m}$ a.g.l.) showed a correlation of $R^{2}$ of 0.99 and an RMSE of $0.6^{\circ} \mathrm{C}$. 


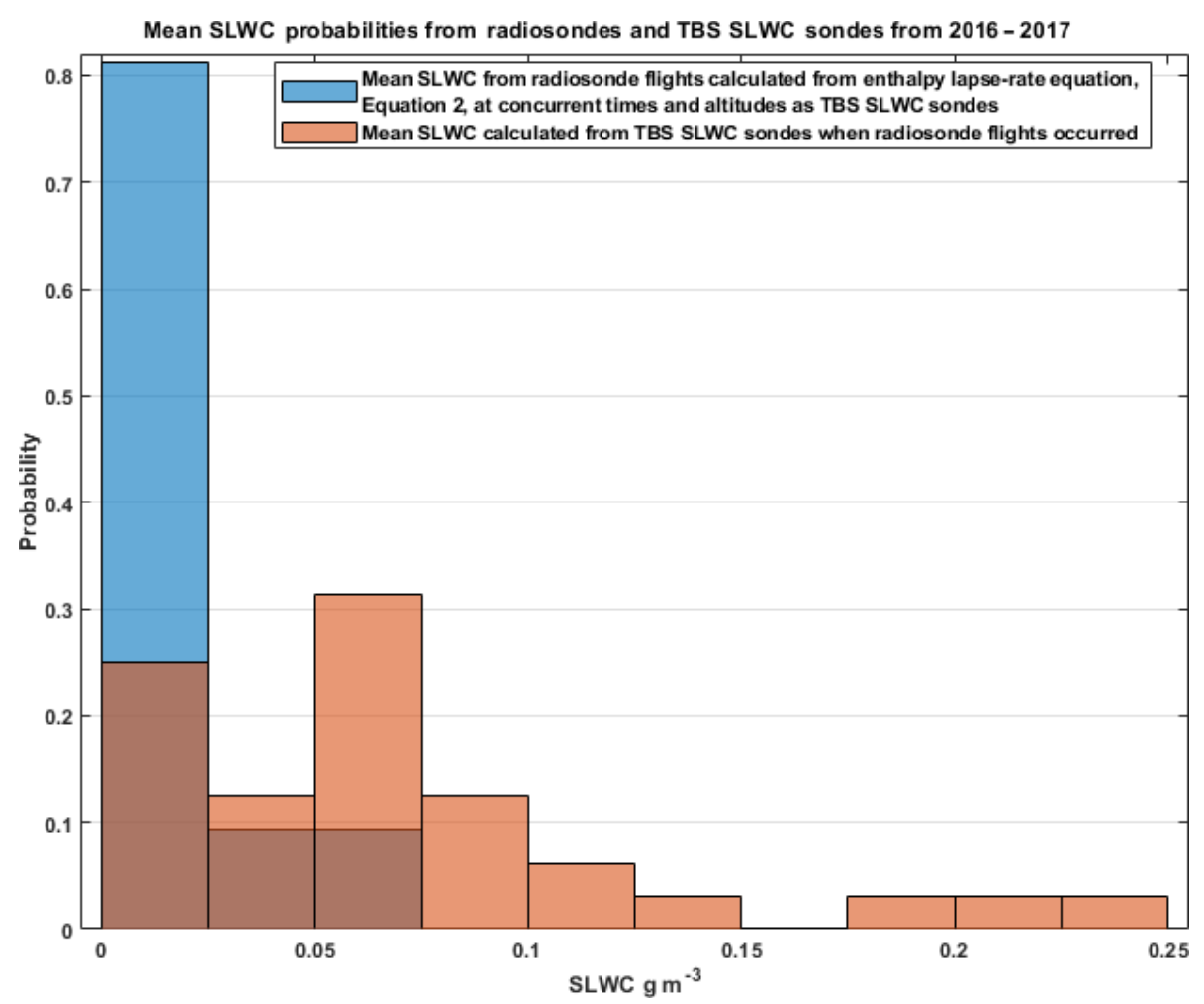

Figure 11. The 2016-2017 Mean SLWC from Anasphere sondes (orange) and mean SLWC calculated from AMF3 radiosonde flights (blue) during TBS flights over the TBS flight altitude range.
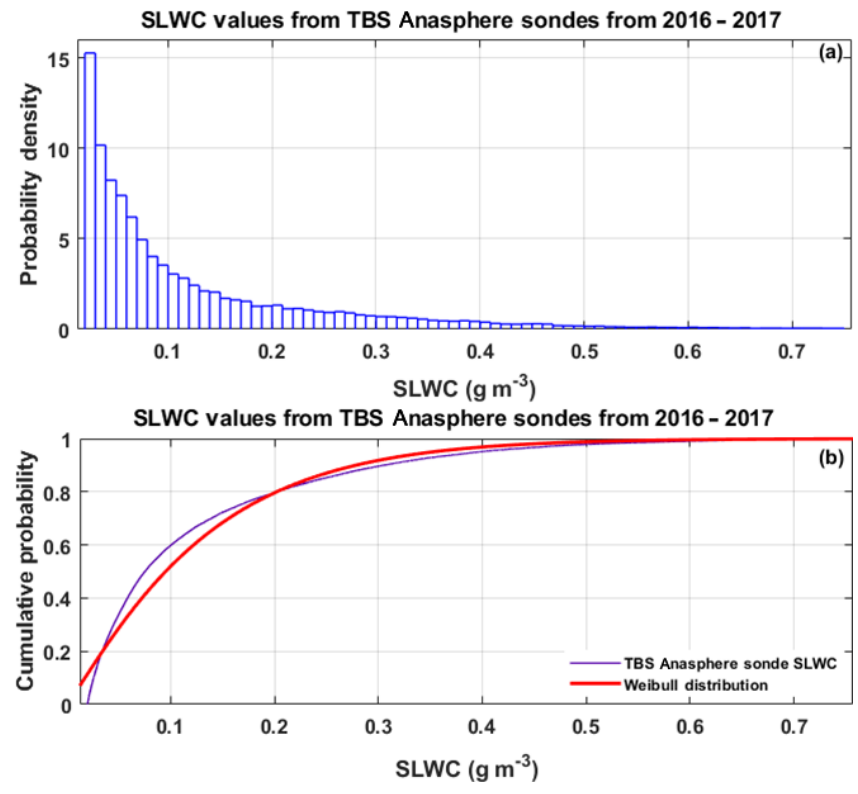

Figure 12. PDF and cumulative distribution function of 2016-2017 TBS Anasphere SLWC sonde data collected over 43 flights.

\subsubsection{Comparison of DTS temperature measurements with TBS iMet radiosonde temperatures at the same altitude}

While the comparison of TBS DTS measurements and freeflight radiosonde measurements is informative, the dataset is limited since only two radiosondes are launched daily from the AMF3. In order to compare a larger number of samples (197 samples over a $20^{\circ} \mathrm{C}$ range were available), temperatures from an iMet radiosonde suspended on the TBS tether were compared with DTS measurements collected at the same altitude over nine TBS flights from 2016 to 2017 (Fig. 16). DTS $1 \mathrm{~m}$ spatial resolution and $60 \mathrm{~s}$ temporal data were averaged over $10 \mathrm{~m}$ to match the simultaneous AMF3 radiosonde vertical resolution. During two of these nine flights two channels were used on the DTS. While the multimode fiber used for TBS DTS measurements is white, some excess heating due to solar radiation could still occur. The iMet radiosonde temperatures are corrected within the collection software SkySonde, which was developed by the National Oceanic and Atmospheric Administration (NOAA), for solar radiation based on solar elevation and flight altitude. The correction factors were derived from a proprietary report developed by InterMet for NOAA (e.g., InterMet, 2009) and are not fixed but are interpolated between the solar elevations and altitudes shown in Table 2. In an effort to correct 

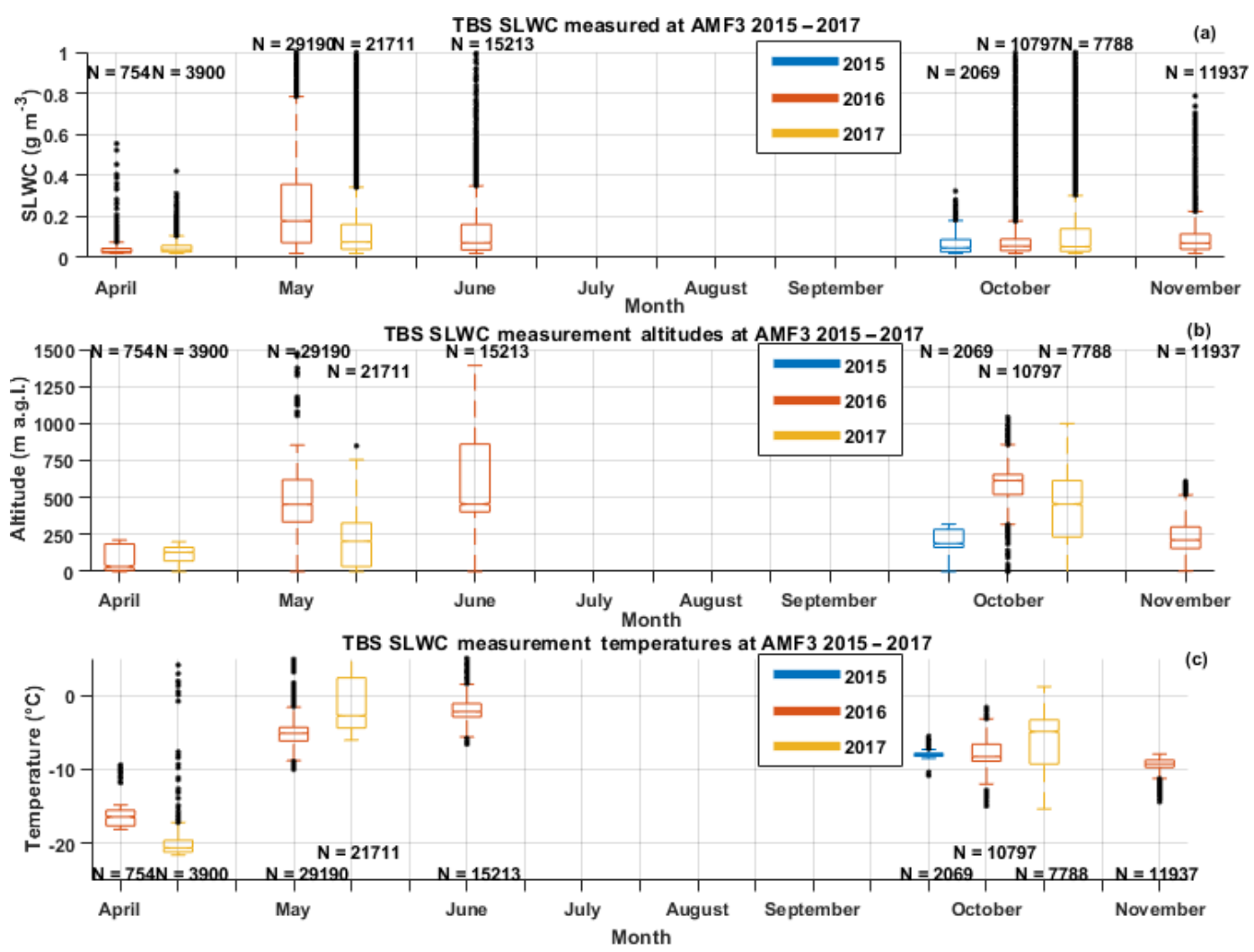

Figure 13. SLWC measured by Anasphere sondes flown on the TBS and SLWC measurement altitudes and temperatures by month from 2015 to 2017, where $N$ refers to the number of SLWC measurements and the median is shown by the horizontal line. The 25 th and 75 th percentiles are shown by the bottom and top edges of the box, the whiskers extend to the data points not considered outliers, and outliers are plotted with "+".

DTS temperatures for excess solar heating, the linear fit between the radiation-corrected iMet radiosonde temperatures and DTS temperatures was applied to the DTS temperature values for each flight. The mean RMSE between the iMet radiosonde temperatures and uncorrected DTS temperatures was $0.39^{\circ} \mathrm{C}$, improving to $0.32^{\circ} \mathrm{C}$ after the corrections were applied to DTS temperatures.

\subsubsection{July 2018 and 11 July 2018 DTS measurements with POPS aerosol instruments}

During the POPEYE field campaign a Silixa XT DTS system was operated on the TBS using $50 \mu \mathrm{m}$ multimode optical fiber suspended along the tether. Temperature measurements were collected every $30-60 \mathrm{~s}$ with a spatial resolution of $0.65 \mathrm{~cm}$. Two POPSs (printed optical particle spectrometers) were suspended along the tether at different altitudes. One POPS was operated just below the balloon in order to reach the maximum possible altitude, which was ideally above cloud top. A second POPS was generally operated several meters lower than the top POPS to sample near the cloud base.
Figure 17 depicts results from 10 July 2018, when the continuous DTS temperature profiles and iMet radiosonde temperatures reveal a cooler layer at the surface below $100 \mathrm{~m}$ with a 1 to $1.5^{\circ} \mathrm{C}$ warmer layer between 150 and $800 \mathrm{~m}$, then another cooler layer above the inversion from $800 \mathrm{~m}$ to $1 \mathrm{~km}$. The AMF3 radiosonde launch at 23:30 UTC measured a similar temperature profile. The particle concentration measured by the POPSs at a sample rate of $1 \mathrm{~Hz}$ demonstrates increased particle concentration within the temperature inversion, with fewer particles above the inversion and in the surface-cooled layer. The surface layer warmed in the afternoon and the base of the inversion layer became higher in altitude with time. An inversion was no longer present at 01:00 UTC, and the boundary layer became warmer and more well-mixed below $1 \mathrm{~km}$. The particle concentrations measured by the POPSs after 01:00 UTC were also similar at both measurement altitudes, which indicated the well-mixed boundary layer in the afternoon.

On 11 July 2018 the surface layer below $200 \mathrm{~m}$ was roughly $2{ }^{\circ} \mathrm{C}$ cooler than on the previous day, as were temperatures in the inversion layer between $200 \mathrm{~m}$ and $1.2 \mathrm{~km}$ (Fig. 18). POPS particle concentrations were elevated within the inversion layer and were similar to the observation on 


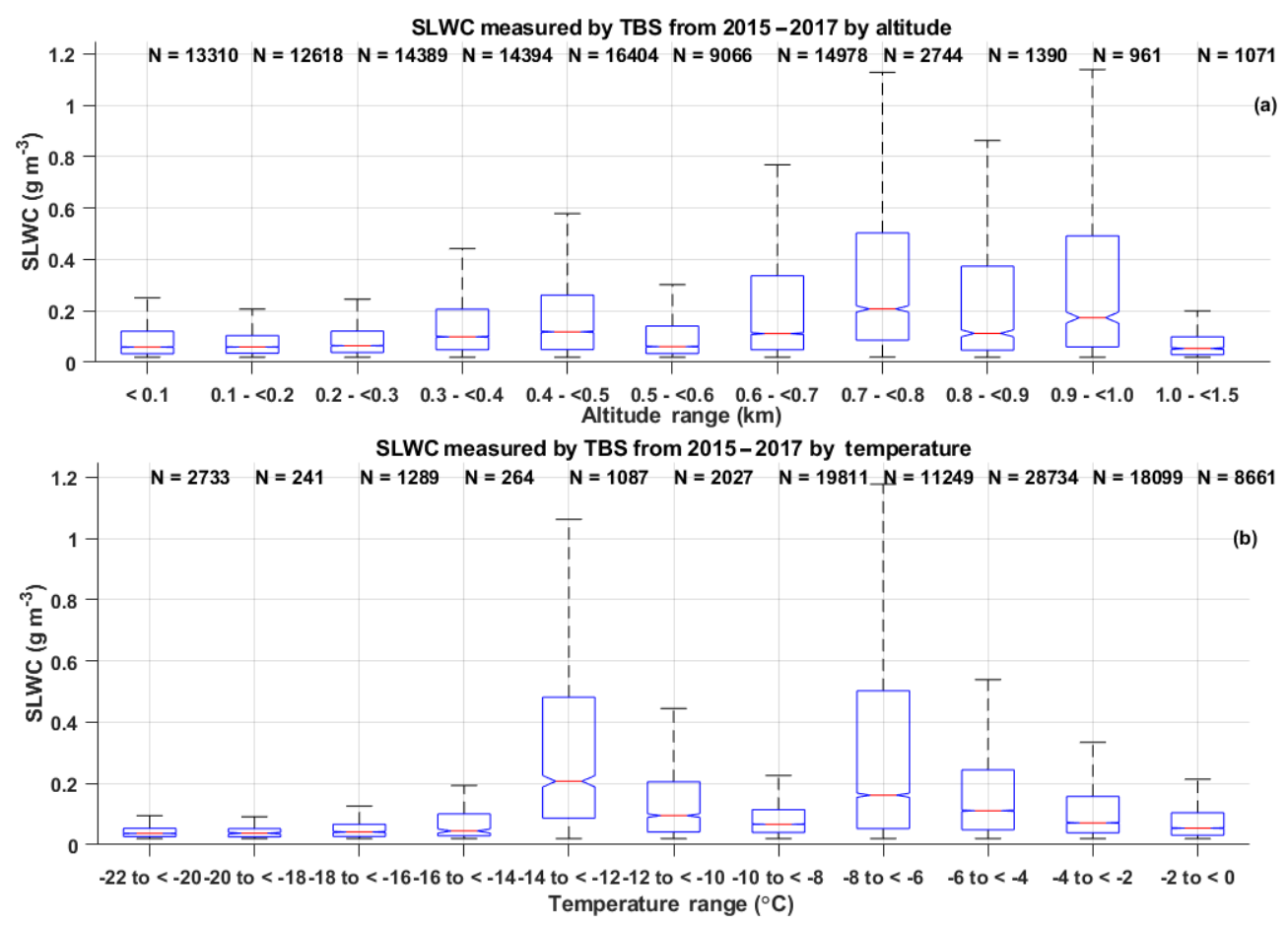

Figure 14. SLWC measured by Anasphere sondes flown on the TBS by altitude and temperature from 2015 to 2017 , where $N$ refers to the number of SLWC measurements and the median is shown by the horizontal line. The 25 th and 75 th percentiles are shown by the bottom and top edges of the box, the whiskers extend to the data points not considered outliers, and outliers are plotted with ' + '.

Table 2. Solar radiation correction factors applied in SkySonde collection software as a function of iMet radiosonde flight altitude and solar elevation.

\begin{tabular}{lrrrrccccc}
\hline Altitude $(\mathrm{km})$ & \multicolumn{10}{c}{ Solar elevation $\left(^{\circ}\right)$} \\
\cline { 2 - 10 } & -7 & -3 & -1 & 2 & 5 & 15 & 30 & 60 & 90 \\
\hline 0 & 0.120 & 0.072 & 0.048 & -0.072 & -0.072 & -0.036 & 0.000 & 0.060 & 0.096 \\
5 & -0.060 & -0.228 & -0.204 & -0.120 & -0.084 & -0.024 & 0.000 & 0.036 & 0.048 \\
10 & -0.228 & -0.336 & -0.192 & -0.120 & -0.120 & -0.024 & 0.000 & 0.036 & 0.048 \\
15 & -0.444 & -0.420 & -0.228 & -0.132 & -0.084 & -0.024 & 0.000 & 0.048 & 0.060 \\
20 & -0.624 & -0.432 & -0.264 & -0.132 & -0.084 & -0.024 & 0.000 & 0.060 & 0.096 \\
25 & -0.828 & -0.468 & -0.276 & -0.144 & -0.096 & -0.036 & 0.000 & 0.084 & 0.120 \\
30 & -1.020 & -0.492 & -0.264 & -0.144 & -0.072 & -0.048 & 0.000 & 0.108 & 0.156 \\
35 & -1.152 & -0.552 & -0.288 & -0.156 & -0.120 & -0.048 & 0.000 & 0.132 & 0.192 \\
\hline
\end{tabular}

the previous day. Unlike the previous day, particle concentrations did not decrease to almost 0 above the inversion layer, indicating a less stratified aerosol profile. The base of the inversion layer decreased between 18:30 and 19:30 UTC, and a shallow $\sim 50 \mathrm{~m}$ deep warm layer was isolated around $400 \mathrm{~m}$ after 19:30 UTC. An iMet radiosonde on the tether corroborated this shallow warm layer measured by the DTS temperature profiles. No clouds were present within the TBS flight altitudes on either day. Elevated temperatures at the surface were caused by friction of the fiber against sharply angled metal tubing as it entered and exited the calibration bath.

\subsubsection{DTS temperature calibration source and fiber optic rotary joint impacts on measurement accuracy}

The DTS collected over 250 samples of $30 \mathrm{~s}$ measurements with two fibers during the POPEYE field campaign. One fiber did not include a rotary joint and was in use only when the balloon was not ascending or descending. The other fiber was installed with a fiber optic rotary joint (FORJ) and measured continuously. The DTS measurements were calibrated with a reference temperature sensor installed on the tether at the maximum-altitude ends of the fibers. An iMet radiosonde and iMet XQ2 sensor were both used to provide reference 


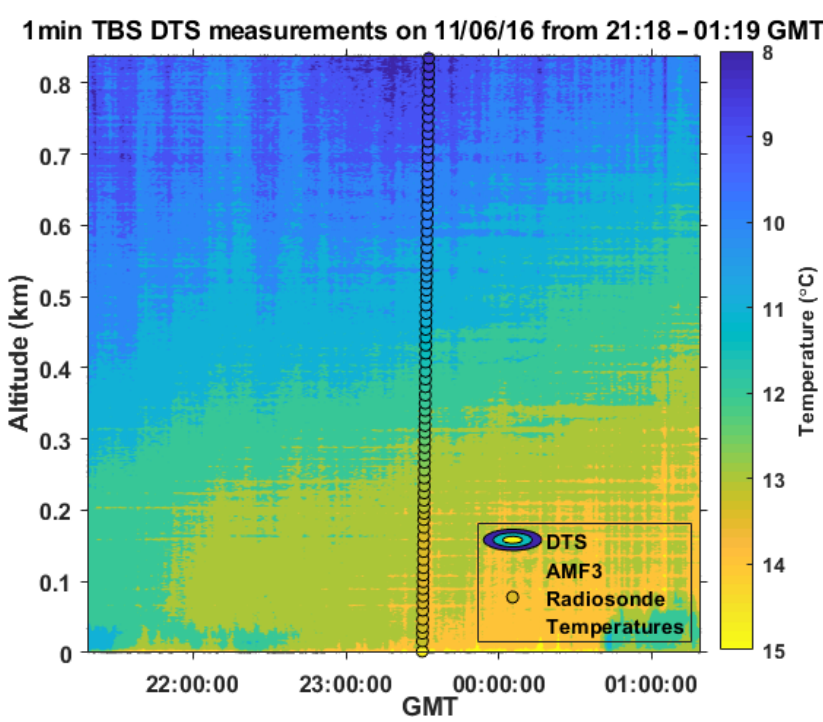

Figure 15. TBS DTS measurements collected once per minute with concurrent free-balloon radiosonde launch at 23:30 UTC.

temperatures. The DTS temperatures were averaged vertically over $5 \mathrm{~m}$ in order to compare with temperatures from simultaneous radiosonde profiles. The average correlation coefficients and RMSEs between the DTS fiber measurements calibrated with the iMet radiosonde or XQ2 sensor, collected with or without a FORJ, and free-flight radiosonde temperatures are shown in Table 3.

The iMet radiosonde and XQ2 sensors performed almost identically as reference temperature sources. The FORJ and non-FORJ temperatures correlated to each other at 0.74 and had an RMSE of $0.5^{\circ} \mathrm{C}$. Both the FORJ and non-FORJ measurements correlated to radiosondes at 0.97 with RMSEs from 0.4 to $0.6^{\circ} \mathrm{C}$. DTS temperature measurements from both fibers with respect to altitude collected during a TBS flight on 26 September 2018 are shown in Fig. 19. The relationship between the DTS temperature measurements from each fiber was consistent across all altitudes.

\section{Conclusions}

In situ, vibrating-wire-based measurements of supercooled liquid water within Arctic clouds collected using a tetheredballoon system have been evaluated against surface-based remote sensing and radiosonde-derived measurements. First, a free-balloon sounding that occurred during the TBS flight was analyzed using the enthalpy equation for cloud water (LWC) in the commercial software RAOB. The supercooled liquid water contents calculated by RAOB from the free-radiosonde flight at the altitudes of two vibrating-wire Anasphere SLWC sondes on the tethered balloon were both $0.14 \mathrm{~g} \mathrm{~m}^{-3}$. The maximum SLWC observed by the highestaltitude SLWC sonde at the time of the radiosonde flight was $0.14 \mathrm{~g} \mathrm{~m}^{-3}$, while the maximum SLWC observed by the lower-altitude sonde was $0.05 \mathrm{~g} \mathrm{~m}^{-3}$. While the absolute uncertainty between the two measurements is difficult to determine given the standard deviation of $120 \mathrm{~m}$ in the cloud base measured by the ceilometer at the time of the radiosonde flight and the spatial variation between the TBS vibrating-wire sonde and $\mathrm{AMF} 3$ radiosonde measurement sites, the TBS Anasphere SLWC sondes and RAOB LWC measurements agree within $0.1 \mathrm{~g} \mathrm{~m}^{-3}$.

Second, SLWC values from in situ TBS Anasphere sondes were compared with adiabatically distributed LWP values from the AMF3 MWR for two TBS flights in October 2016. During the first flight the cloud base varied significantly. Both SLW measurements closely identified the occurrence of SLW in time, although the magnitude differed, resulting in an $R^{2}$ value of 0.38 . Again, given the uncertainties in the cloud base height, the altitude of the vibrating-wire sonde, and the relative positions of each, the temporal agreement of SLWC detection between the two sensors is significant. For the second flight the $R^{2}$ value was 0.79 , with MWR SLWC values averaging $0.03 \mathrm{~g} \mathrm{~m}^{-3}$ higher. The low bias of the TBS SLWC sonde can be partially attributed to the vibrating wire experiencing maximum ice loading and incompletely shedding multiple times during the flight, resulting in slightly low SLWC values, due to the failure of the wire to completely return to its un-iced initial frequency.

The Anasphere sensor was deployed alongside an alternative SLWC sensor developed at the University of Reading in order to compare data sensed using different available vibrating-wire-based sensors. There was general good agreement between the two vibrating sensors and also between them and the MWR measurements (LWP $\pm 0.008 \mathrm{~mm}$ for the Reading sensor and $\pm 0.003 \mathrm{~mm}$ for the Anasphere sensor during ascents and $0.1 \mathrm{~g} \mathrm{~m}^{-3}$ RMSE between the two sensors for the flight). Some potential for additional variation related to ice load saturation and instrument geometry may be important and should be considered when comparing data collected using different sensors.

Mean values of SLWC from the Anasphere sondes deployed on the TBS for 43 flights were compared with mean SLWC values calculated from AMF3 radiosonde soundings that occurred during each TBS flight using the enthalpy lapse-rate equation for cloud water (LWC) in the commercial software RAOB. The mean SLWC values measured by the in situ vibrating-wire sondes averaged $0.045 \mathrm{~g} \mathrm{~m}^{-3}$ higher than the mean SLWC values calculated from the radiosonde flights. SLWC values from vibrating sondes were $<0.05 \mathrm{~g} \mathrm{~m}^{-3}$ for $34 \%$ of the samples, which is in agreement with previous aircraft measurements in supercooled stratiform clouds of $<0.05 \mathrm{~g} \mathrm{~m}^{-3}$ for $36 \%$ of the samples (e.g., University of Wyoming, 1999).

Recurring TBS Anasphere SLWC sonde deployments occurred at the ARM AMF3 during fall and spring months between 2015 and 2017. The largest SLWC values were measured during May and June, with smaller values being measured in fall and early spring. Larger SLWC values were mea- 


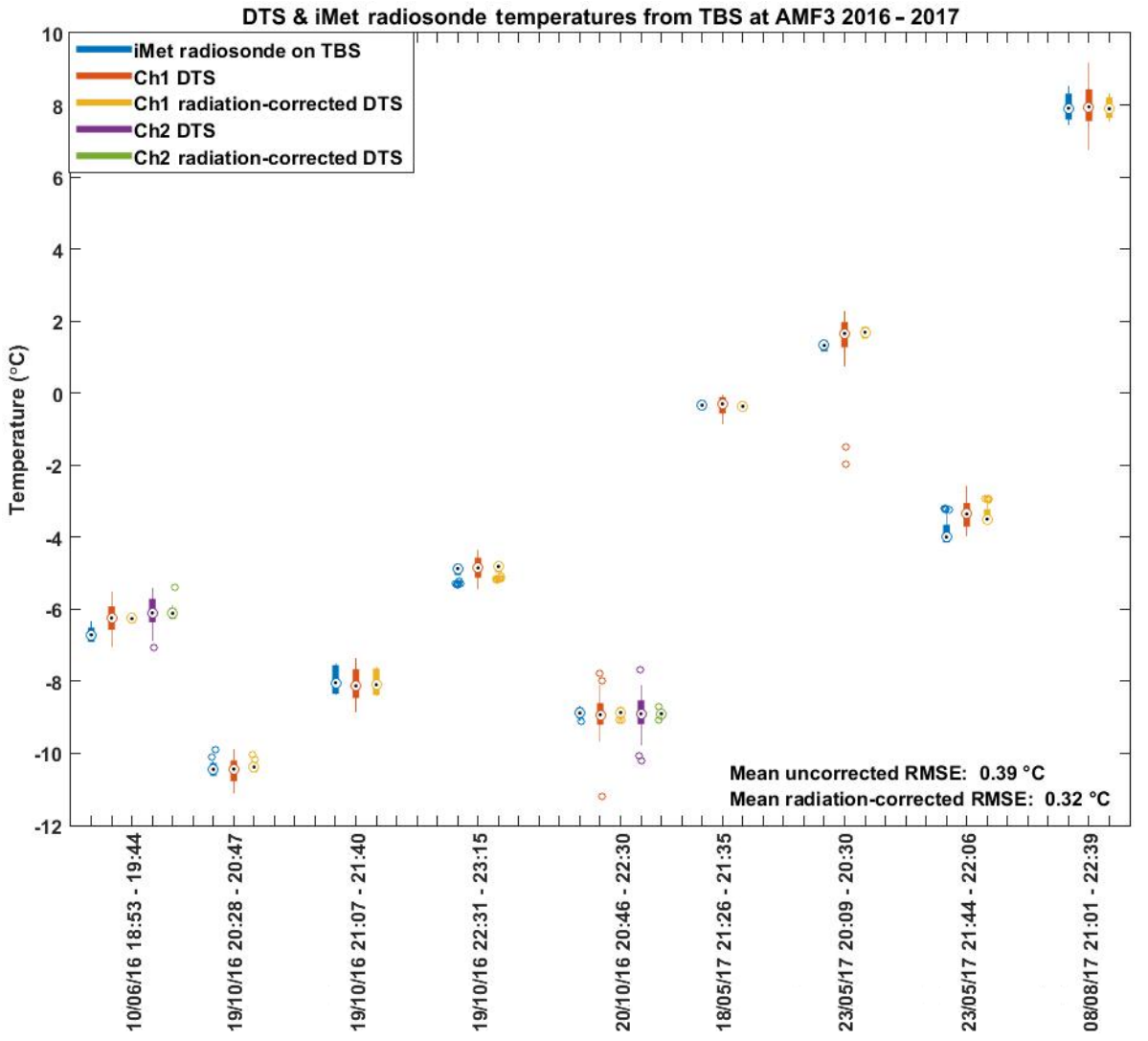

Figure 16. DTS and iMet radiosonde temperatures at matching altitudes from nine TBS flights at the AMF3 from 2016 to 2017.

Table 3. Correlation coefficients and RMSEs for iMet-1-RSB radiosonde or iMet XQ2-calibrated DTS data, and DTS data collected with or without a fiber optic rotary joint (FORJ).

\begin{tabular}{lcc}
\hline & Correlation & RMSE $\left({ }^{\circ} \mathrm{C}\right)$ \\
\hline Mean iMet-calibrated, XQ-2-calibrated & 0.76 & 0.49 \\
Mean iMet-calibrated FORJ, iMet-calibrated non-FORJ & 0.74 & 0.51 \\
Mean XQ2-calibrated FORJ, XQ2-calibrated non-FORJ & 0.74 & 0.50 \\
FORJ iMet-calibrated vs. radiosonde & 0.97 & 0.49 \\
FORJ XQ2-calibrated vs. radiosonde & 0.97 & 0.60 \\
Non-FORJ iMet-calibrated vs. radiosonde & 0.97 & 0.43 \\
Non-FORJ XQ2-calibrated vs. radiosonde & 0.97 & 0.46 \\
\hline
\end{tabular}

sured above $400 \mathrm{~m}$ altitude and at temperatures between -14 and $-2{ }^{\circ} \mathrm{C}$.

DTS measurements collected between the surface and the balloon were compared with concurrent radiosonde temperature measurements. The effect of different calibration measurement source instruments upon the DTS measurement accuracy was evaluated, as was the use of a fiber optic rotary joint. Radiosonde and DTS temperature measurements between the surface and the maximum altitude of the fiber, $0.84 \mathrm{~km}$ a.g.l., correlated with an $R^{2}$ of 0.99 and an RMSE of $0.6^{\circ} \mathrm{C}$. In order to compare a larger number of samples (197 samples over a $20^{\circ} \mathrm{C}$ range), temperatures from an iMet radiosonde suspended on the TBS tether were compared with DTS measurements collected at the same altitude over nine TBS flights from 2016 to 2017. The mean RMSE between the iMet radiosonde temperatures and uncorrected DTS temperatures was $0.39^{\circ} \mathrm{C}$, improving to $0.32^{\circ} \mathrm{C}$ after solar radiation correction factors were applied to DTS temperatures.

DTS temperature measurements collected with and without a fiber optic rotary joint correlated to each other at 0.74 and had an RMSE of $0.5^{\circ} \mathrm{C}$. FORJ DTS measurements had an average correlation of 0.97 with radiosonde temperatures, and RMSE values of 0.5 and $0.6^{\circ} \mathrm{C}$ for the iMet-1-RSB 


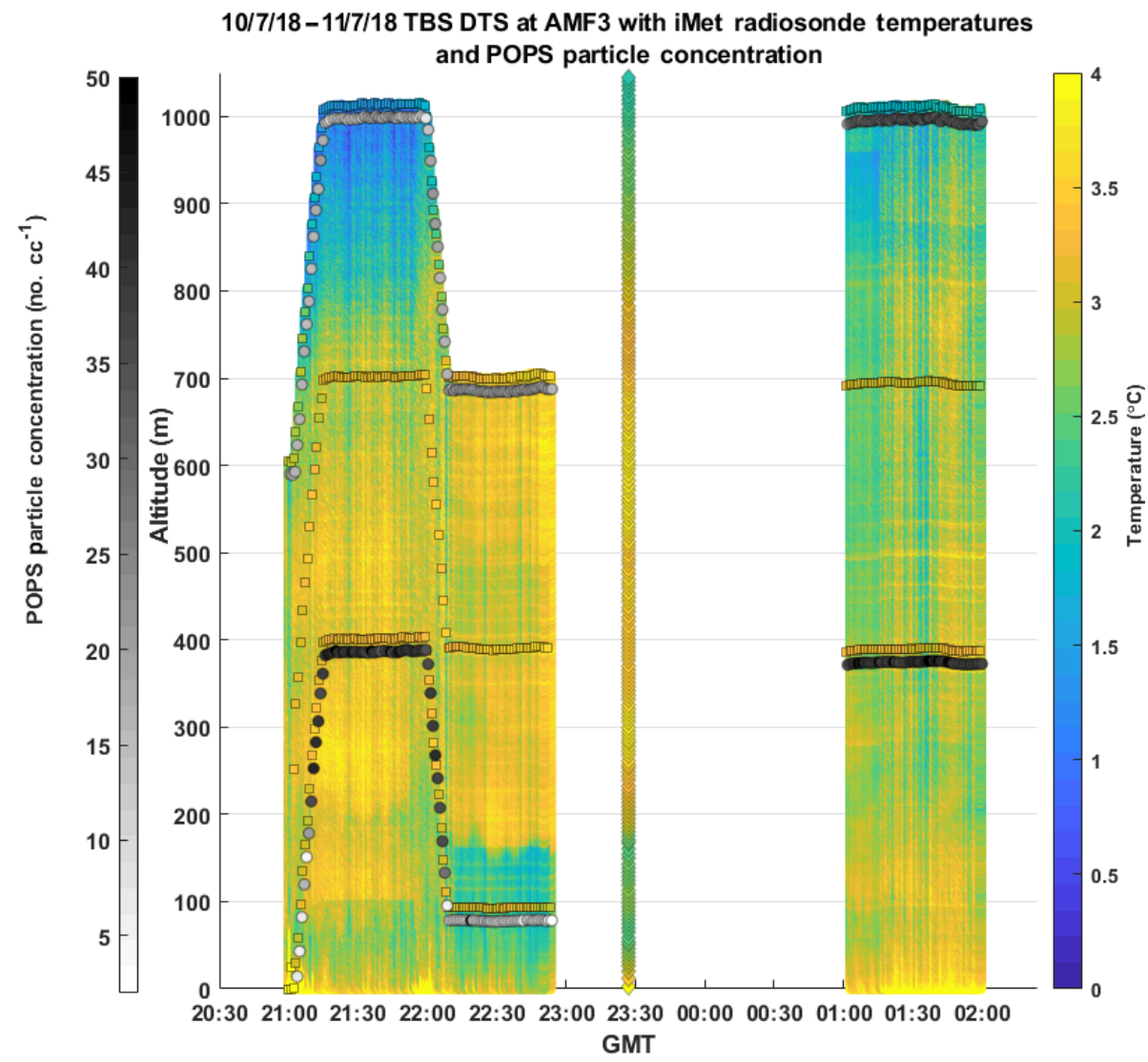

Figure 17. The 10-11 July 2018 TBS DTS profiles at AMF3 with TBS iMet temperatures (squares), free-flight radiosonde temperatures (diamonds), and POPS particle concentrations (circles).

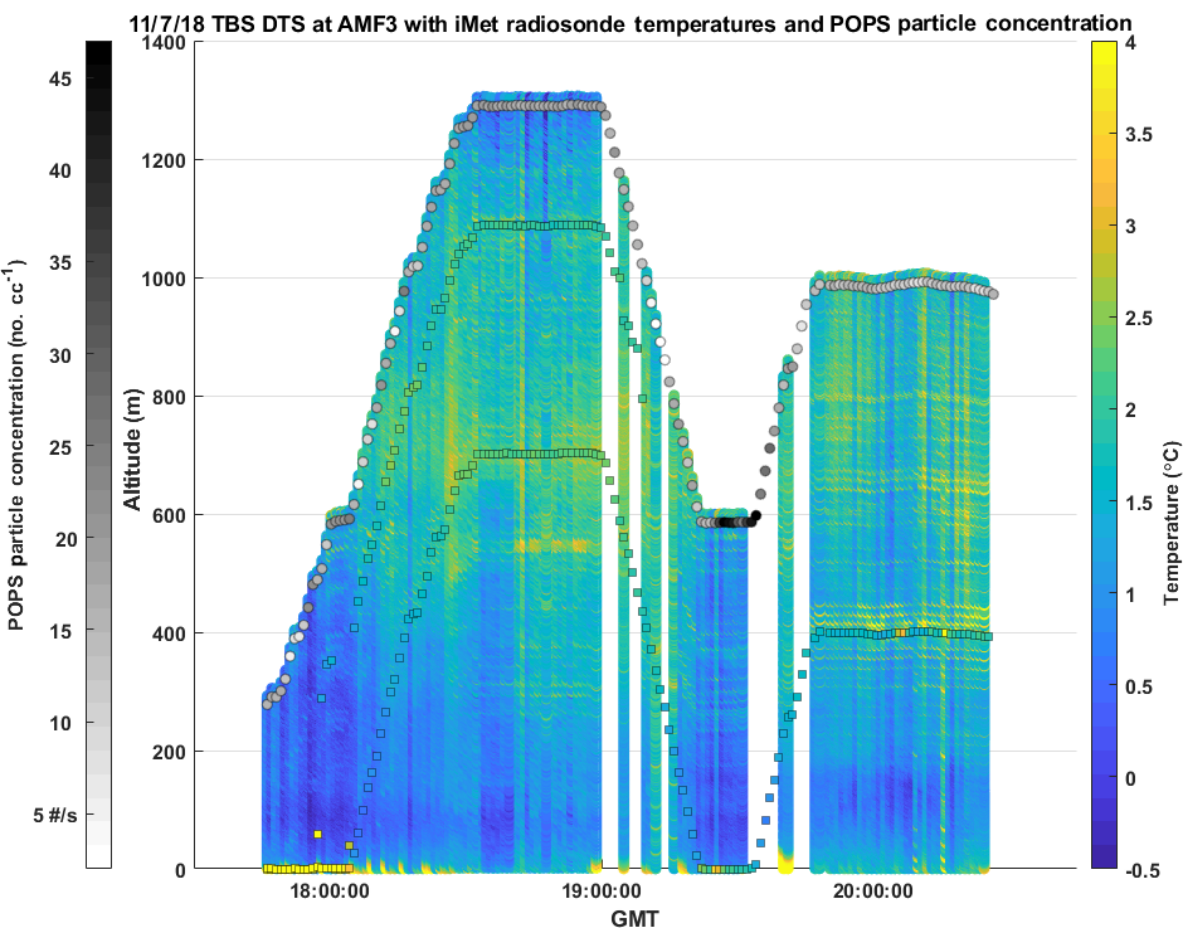

Figure 18. The 11 July 2018 TBS DTS profiles at AMF3 with TBS iMet temperatures (squares) and POPS particle concentrations (circles). 


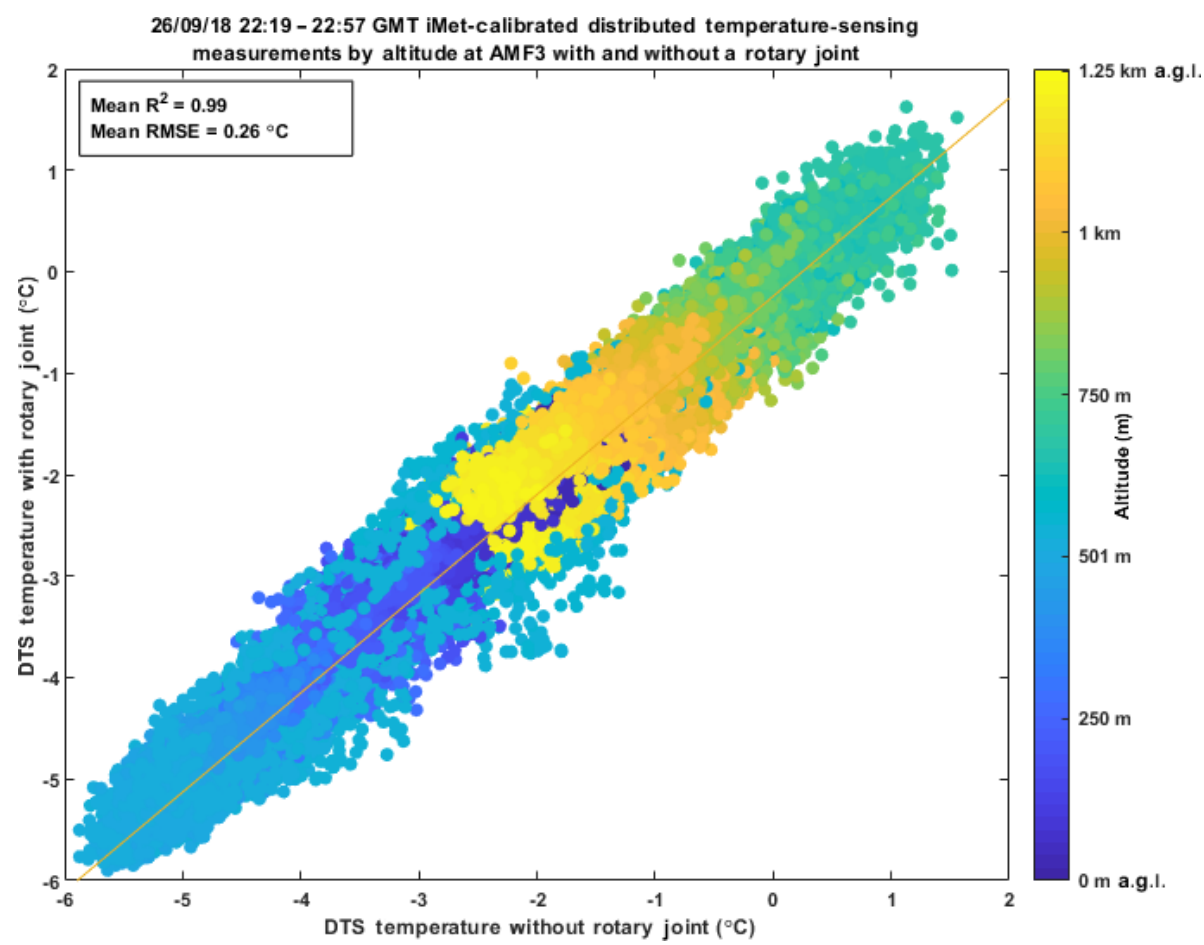

Figure 19. The 26 September 2018 TBS DTS measurements with and without a fiber optic rotary joint (FORJ).

radiosonde and iMet XQ2-calibrated DTS datasets, respectively. The non-FORJ DTS measurements had an identical average correlation of 0.97 with radiosonde temperatures, and RMSE values of 0.43 and $0.46^{\circ} \mathrm{C}$ for the iMet-1-RSB and iMet XQ2-calibrated DTS datasets, respectively.

The similar RMSE values between the DTS and radiosonde datasets both with and without an installed FORJ indicates the presence of the FORJ has a very limited impact on the measurement accuracy of DTS measurements. For context, the stated temperature measurement accuracies are $\pm 0.2, \pm 0.3$, and $\pm 0.2^{\circ} \mathrm{C}$, for the iMet-1-RSB radiosonde, iMet XQ2, and Vaisala RS-92 sensors, respectively. The average RMSE of $0.4-0.6^{\circ} \mathrm{C}$ between DTS temperature and radiosonde temperature measurements indicates DTS measurements from TBSs provide accurate, highly spatially and temporally resolved, persistent temperature profiles within the lowest $2 \mathrm{~km}$ of the atmosphere. The approximate average RMSE of $0.5^{\circ} \mathrm{C}$ between the DTS measurements and Vaisala radiosonde measurements may partially be attributed to spatial disparity between the tethered and freeflight sensors, noting that free-flight radiosonde launches were intentionally launched upwind of the tethered balloon during simultaneous flights to avoid potential entanglement. Additional differences in temperature measurement may be due to measurement bias between the iMet-1-RSB radiosondes and iMet XQ2 sensors used to calibrate the TBS DTS measurements, and the Vaisala RS-92 sondes used in AMF3 radiosonde launches. Some RMSEs may also be attributed to uncertainty in the GPS-reported altitude from each sensor, given the stated vertical accuracy of $\pm 12 \mathrm{~m}$ of the iMet XQ2 sensor, $\pm 15 \mathrm{~m}$ of the iMet-1-RSB, and $\pm 20 \mathrm{~m}$ of the Vaisala RS-92. The relationship between iMet sensor temperatures and Vaisala radiosonde temperatures will be investigated in future TBS flights.

Data availability. TBS Anasphere SLWC sonde (e.g., Dexheimer and Shi, 2016; https://doi.org/10.5439/1246826), TBS iMet radiosonde (e.g., Dexheimer and Cromwell, 2017; https://doi.org/10.5439/1426242), TBS POPS, ceilometer (e.g., Johnson et al., 2013; https://doi.org/10.5439/1181954), KAZR (e.g., Matthews et al., 2015; https://doi.org/10.5439/1025214), MWR (e.g., Cadeddu and Ghate, 2013; https://doi.org/10.5439/1025248), Doppler lidar (e.g., Riihimaki et al., 2013; https://doi.org/10.5439/1190027), KAZRARSCL (e.g., Johnson et al., 2015; https://doi.org/10.5439/1350629), and radiosonde (e.g., Coulter et al., 2013; https://doi.org/10.5439/1021460) data related to this article are available from the ARM Data Discovery website and more specific information is listed in the references. TBS DTS data and some SLWC data are in the process of being made available on the ARM Data Discovery website.

Author contributions. DD and MA analyzed the data and drafted the paper. DD and CL conducted the experiments. ER guided the deployment of the Anasphere SLWC sondes. MA, KN, RGH, GM, and PDW developed the Reading SLWC sensor and contributed to 
the writing of the paper. SK provided guidance on the comparison of sonde SLWC and MWR data and contributed to the writing of the paper. FM provided expertise on TBS POPS data and contributed to the writing of the paper.

Competing interests. The authors declare that they have no conflict of interest.

Acknowledgements. We gratefully acknowledge the U.S. Department of Energy Atmospheric Radiation Measurement program and Sandia National Laboratories for logistics support. This work was supported in part by the Laboratory Directed Research and Development program at Sandia National Laboratories, a multi-mission laboratory managed and operated by National Technology and Engineering Solutions of Sandia, LLC., a wholly owned subsidiary of Honeywell International Inc., for the U.S. Department of Energy's National Nuclear Security Administration under contract DE-NA0003525. MA, KN, RGH, PDW, and GM acknowledge support from NERC grant no. NE/P003362/1 (VOLCLAB) for development of the Reading SLWC sensor. KN acknowledges support through the NERC Environmental Bioinformatics Centre (grant nos. NE/L011514/1, NE/L011514/2). SK was supported by the Deutsche Forschungsgemeinschaft (DFG, German Research Foundation) under grant KN 1112/2-1 as part of the Emmy-Noether Group OPTIMIce.

The authors wish to thank Gijs de Boer for leading the ARM ICARUS and POPEYE field campaigns. John Shewchuk of Eosonde Research Services provided documentation regarding RAOB software calculations. John Bognar of Anasphere aided in the development of the SLWC Anasphere sonde data processing methodology. David Serke of UCAR provided guidance regarding the collection of SLWC data in flight. Allen Jordan and Emrys Hall of NOAA developed the SkySonde software for iMet radiosondes that was used to collect all iMet radiosonde-derived data used in this research. We thank CTEMPs, funded by the National Science Foundation (EAR awards 1440596 and 1440506), for providing initial training on the use of DTS and DTS data processing. Mark Benoit of InterMet provided technical support regarding iMet radiosondes and XQ2 sensors.

Financial support. This research has been supported by the Department of Energy, Labor and Economic Growth (grant no. DENA0003525), the NERC Environmental Bioinformatics Centre (grant no. NE/P003362/1), the NERC Environmental Bioinformatics Centre (grant no. NE/L011514/1), and the Deutsche Forschungsgemeinschaft (grant no. KN 1112/2-1).

Review statement. This paper was edited by Szymon Malinowski and reviewed by two anonymous referees.

\section{References}

Airey, M. W., Harrison, R. G., Nicoll, K. A., Williams, P. D., and Marlton, G. J.: Note: A miniature oscillating microbalance for sampling ice and volcanic ash from a small airborne platform, Rev. Sci. Instrum., 88, 086108, https://doi.org/10.1063/1.4998971, 2017.

Bain, M. and Gayet, J. F.: Aircraft measurements of icing in supercooled and water droplet/ice crystal clouds, J. Appl. Meteorol., 21, 631-641, https://doi.org/10.1175/15200450(1982)021<0631:AMOIIS>2.0.CO;2, 1982.

Cadeddu, M. and Ghate, V.: Microwave Radiometer, 3 Channel (MWR3C). 2015-10-15 to 2018-10-01, ARM Mobile Facility (OLI) Oliktok Point, Alaska; AMF3 (M1), Atmospheric Radiation Measurement (ARM) user facility Data Center, updated hourly, https://doi.org/10.5439/1025248, 2013.

Cortland Company, Inc.: LoCo 12 Strand Tech Sheet, CT_TL_047_1112_US, 2019.

Coulter, R., Holdridge, D., and Kyrouac, J.: Balloon-Borne Sounding System (SONDEWNPN). 2018-07-01 to 2018-10-01, ARM Mobile Facility (OLI) Oliktok Point, Alaska; AMF3 (M1), Atmospheric Radiation Measurement (ARM) user facility Data Center, updated hourly, https://doi.org/10.5439/1021460, 2013.

Crewell, S., Ebell, K., Loehnert, U., and Turner, D.: Can liquid water profiles be retrieved from passive microwave zenith observations?, Geophys. Res. Lett., 36, L06803, https://doi.org/10.1029/2008GL036934, 2009.

de Jong, S. A. P., Slingerland, J. D., and van de Giesen, N. C.: Fiber optic distributed temperature sensing for the determination of air temperature, Atmos. Meas. Tech., 8, 335-339, https://doi.org/10.5194/amt-8-335-2015, 2015.

Dexheimer, D.: Tethered Balloon System (TBS) Instrument Handbook, edited by: Stafford, R., ARM Climate Research Facility, DOE/SC-ARM-TR-206, 2018.

Dexheimer, D. and Cromwell, E.: Tethered Balloon System (TBSIMET). 2017-05-15 to 2018-10-01, ARM Mobile Facility (OLI) Oliktok Point, Alaska; AMF3 (M1), Atmospheric Radiation Measurement (ARM) user facility Data Center, updated hourly, https://doi.org/10.5439/1426242, 2017.

Dexheimer, D. and Shi, Y.: Tethered Balloon System (TBSSLWC). 2016-05-14 to 2018-10-01, ARM Mobile Facility (OLI) Oliktok Point, Alaska; AMF3 (M1), Atmospheric Radiation Measurement (ARM) user facility Data Center, updated hourly, https://doi.org/10.5439/1246826, 2016.

Egerer, U., Gottschalk, M., Siebert, H., Ehrlich, A., and Wendisch, M.: The new BELUGA setup for collocated turbulence and radiation measurements using a tethered balloon: first applications in the cloudy Arctic boundary layer, Atmos. Meas. Tech., 12, 4019-4038, https://doi.org/10.5194/amt-12-4019-2019, 2019.

Fernández-González, S., Sánchez, J., Gasćon, E., López, L., GarcíaOrtega, E., and Merino, A.: Weather features associated with aircraft icing conditions: a case study, Sci. World J., 2014, 279063 , https://doi.org/10.1155/2014/279063, 2014.

Greenberg, J., Guenther, A., Zimmerman, P., Baugh, W., Geron, C., Davis, K., Helmig, D., and Klinger, L.: Tethered balloon measurements of biogenic VOCs in the atmospheric boundary layer, Atmos. Environ., 33, 855-867, https://doi.org/10.1016/S1352-2310(98)00302-1, 1999.

Gultepe, I. and Isaac, G. A.: Liquid water content and temperature relationship from aircraft observations and its applicability to 
GCMs, J. Climate, 10, 447-452, https://doi.org/10.1175/15200442(1997)010<0446:LWCATR>2.0.CO;2, 1997.

Harrison, R. G., Nicoll, K. A., and Lomas, A. G.: Note: Programmable data acquisition system for research measurements from meteorological radiosondes, Rev. Sci. Instrum., 83, 036106, https://doi.org/10.1063/1.3697717, 2012.

Hill, G. E.: Analysis of Supercooled Liquid Water Measurements Using Microwave Radiometer and Vibrating Wire Devices, J. Atmos. Ocean. Tech., 11, 1242-1252, https://doi.org/10.1175/15200426(1994)011<1242:AOSLWM>2.0.CO;2, 1994.

Hill, G. E. and Woffinden, D.: A Balloonborne Instrument for the Measurement of Vertical Profiles of Supercooled Liquid Water Concentration, J. Appl. Meteorol., 19, 1285-1292, https://doi.org/10.1175/15200450(1980)019<1285:ABIFTM>2.0.CO;2, 1980.

International Met Systems: Temperature Radiation Error Correction Analysis Report, DIN-A037-R1-03, Silver Spring, Maryland, United States, 2009.

Johnson, K., Giangrande, S., and Toto, T.: Ceilometer (CEIL). 2016-10-15 to 2018-10-01, ARM Mobile Facility (OLI) Oliktok Point, Alaska; AMF3 (M1), compiled by: Ermold, B. and Morris, V., Atmospheric Radiation Measurement (ARM) user facility Data Center, updated hourly, https://doi.org/10.5439/1181954, 2013.

Johnson, K., Giangrande, S., and Toto, T.: Active Remote Sensing of CLouds (ARSCL) product using Ka-band ARM Zenith Radars (ARSCLKAZR1KOLLIAS), ARM Mobile Facility (GAN), https://doi.org/10.5439/1350629, 2015.

Jouan, C., Girard, E., Pelon, J., Gultepe, I., Delanoë, J., and Blanchet, J.-P.: Characterization of Arctic ice cloud properties observed during ISDAC, J. Geophys. Res., 117, D23207, https://doi.org/10.1029/2012JD017889, 2012.

Keller, C. A., Huwald, H., Vollmer, M. K., Wenger, A., Hill, M., Parlange, M. B., and Reimann, S.: Fiber optic distributed temperature sensing for the determination of the nocturnal atmospheric boundary layer height, Atmos. Meas. Tech., 4, 143-149, https://doi.org/10.5194/amt-4-143-2011, 2011.

King, M., Bognar, J., and Guest, D.: Vibrating-Wire, Supercooled Liquid Water Content Sensor Calibration and Characterization Progress, 8th AIAA Atmospheric and Space Environments Conference, 13-17 June 2016, Washington, D.C., AIAA AVIATION Forum, AIAA, 2016-4055, https://doi.org/10.2514/6.2016-4055, 2016.

Knapp, K. G., Jensen, M. L., Balsley, B. B., Bognar, J. A., Oltmans, S. J., Smith, T. W., and Birks, J. W.: Vertical profiling using a complementary kite and tethered balloon platform at Ferryland Downs, Newfoundland, Canada: Observation of a dry, ozonerich plume in the free troposphere, J. Geophys. Res., 103, 1338913397, https://doi.org/10.1029/97JD01831, 1998.

Lawson, R. P., Stamnes, K., Stamnes, J., Zmarzly, P., Koskuliks, J., Roden, C., Mo, Q., Carrithers, M.: Deployment of a Tethered Balloon System for Cloud Microphysics and Radiative Measurements at Ny-Ålesund and South Pole, J. Atmos. Oceanic Technol. 28, 656-670, https://doi.org/10.1175/2010jtecha1439.1, 2011.

Lozowski, E. P., Stallabrass, J. R., and Hearty, P. F.: The Icing of an Unheated, Nonrotating Cylinder Part I: A Simulation Model, J. Clim. Appl. Mete- orol., 22, 2053-2062, https://doi.org/10.1175/15200450(1983)022<2053:TIOAUN>2.0.CO;2, 1983.

Matthews, A., Isom, B., Nelson, D., Lindenmaier, I., Hardin, J., Johnson, K., and Bharadwaj, N.: Ka ARM Zenith Radar (KAZRGE). 2015-10-15 to 2018-10-01, ARM Mobile Facility (OLI) Oliktok Point, Alaska; AMF3 (M1), Atmospheric Radiation Measurement (ARM) user facility Data Center, updated hourly, https://doi.org/10.5439/1025214, 2015.

Morris, A., Call, D., and McBeth, R.: A small tethered balloon sounding system, B. Am. Meteorol. Soc., 56, 964-969, https://doi.org/10.1175/15200477(1975)056<0964:ASTBSS>2.0.CO;2, 1975.

Morris, V. R.: Ceilometer Instrument Handbook, United States, Technical Report DOE/SC-ARM-TR-020, https://doi.org/10.2172/1036530, 2016.

Morrison, H., De Boer, G., Feingold, G., Harrington, J., Shupe, M. D., and Sulia, K..: Resilience of persistent Arctic mixed-phase clouds, Nat. Geosci., 5, 11-17, https://doi.org/10.1038/ngeo1332, 2012.

Owens, T. L., Storey, R. W., and Youngbluth, O.: NASA Langley Research Center Tethered Balloon System, NASA TM-83260, 43 pp., 1987.

Riihimaki, L., Newsom, R., and Shippert, T.: Doppler Lidar Profiles (DLPROFWIND4NEWS). 2016-10-15 to 2018-10-01, ARM Mobile Facility (OLI) Oliktok Point, Alaska; AMF3 (M1), Atmospheric Radiation Measurement (ARM) user facility Data Center, updated hourly, https://doi.org/10.5439/1190027, 2014.

Sand, W. R., Cooper, W. A., Politovich, M. K., and Veal, D. L.: Icing Conditions Encountered by a Research Aircraft, J. Clim. Appl. Meteorol., 23, 1427-1440, https://doi.org/10.1175/07333021-23.10.1427, 1984.

Serke, D., Hall, E., Bognar, J., Jordan, A., Abdo, S., Baker, K., Seitel, T., Nelson, M., Reehorst, A., Ware, R., McDonough, F., and Politovich, M.: Supercooled liquid water content profiling case studies with a new vibrating wire sonde compared to a ground-based microwave radiometer, Atmos. Res., 149, 77-87, https://doi.org/10.1016/j.atmosres.2014.05.026, 2014.

Shupe, M. D. and Intrieri, J. M.: Cloud radiative forcing of the Arctic surface: The influence of cloud properties, surface albedo, and solar zenith angle, J. Climate, 17, 616-628, https://doi.org/10.1175/15200442(2004)017<0616:CRFOTA>2.0.CO;2, 2004.

Shupe, M. D., Persson, P. O. G., Brooks, I. M., Tjernström, M., Sedlar, J., Mauritsen, T., Sjogren, S., and Leck, C.: Cloud and boundary layer interactions over the Arctic sea ice in late summer, Atmos. Chem. Phys., 13, 9379-9399, https://doi.org/10.5194/acp13-9379-2013, 2013.

Thomas, C. K., Kennedy, A. M., Selker, J. S., Moretti, A., Schroth, M. H., Smoot, A. R., and Zeeman, M. J.: High-resolution fibre-optic temperature sensing: a new tool to study the twodimensional structure of atmospheric surface-layer flow, Bound.Lay. Meteorol., 142, 177-192, https://doi.org/10.1007/s10546011-9672-7, 2012.

University of Wyoming, http://www-das.uwyo.edu/ geerts/cwx/ notes/chap08/moist_cloud.html (last access: 28 June 2019), 1999. 